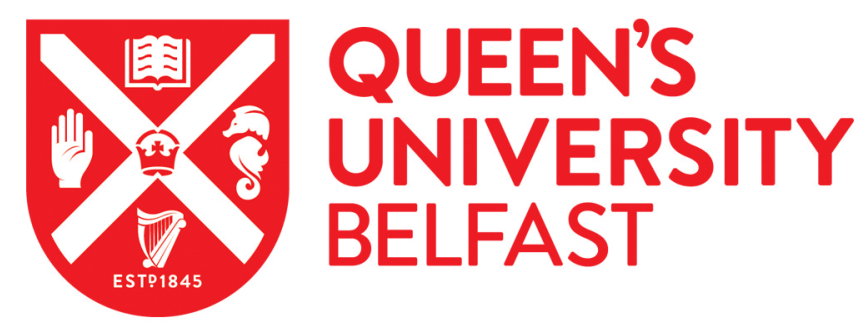

\title{
Alcoholic beverage preference and diabetes incidence across Europe the Consortium on Health and Ageing Network of Cohorts in Europe and the United States (CHANCES) project
}

Sluik, D., Jankovic, N., O'Doherty, M. G., Schöttker, B., Drygas, W., Rolandsson, O., Männistö, S., OrdóñezMena, J. M., Ferrieres, J., Bamia, C., de Gaetano, G., Kiefte-de Jong, J. C., Franco, O. H., Sluijs, I., Spijkerman, A. M. W., Sans, S., Eriksson, S., Kromhout, D., Trichopoulou, A., ... Feskens, E. J. M. (2017). Alcoholic beverage preference and diabetes incidence across Europe the Consortium on Health and Ageing Network of Cohorts in Europe and the United States (CHANCES) project. European Journal of Clinical Nutrition, 71(5), 659668. https://doi.org/10.1038/ejcn.2017.4

Published in:

European Journal of Clinical Nutrition

Document Version:

Peer reviewed version

Queen's University Belfast - Research Portal:

Link to publication record in Queen's University Belfast Research Portal

\section{Publisher rights}

(C) 2017 Macmillan Publishers Limited

This work is made available online in accordance with the publisher's policies. Please refer to any applicable terms of use of the publisher.

\section{General rights}

Copyright for the publications made accessible via the Queen's University Belfast Research Portal is retained by the author(s) and / or other copyright owners and it is a condition of accessing these publications that users recognise and abide by the legal requirements associated with these rights.

Take down policy

The Research Portal is Queen's institutional repository that provides access to Queen's research output. Every effort has been made to ensure that content in the Research Portal does not infringe any person's rights, or applicable UK laws. If you discover content in the Research Portal that you believe breaches copyright or violates any law, please contact openaccess@qub.ac.uk. 
Alcoholic beverage preference and diabetes incidence across Europe: the Consortium on

Health and Ageing Network of Cohorts in Europe and the United States (CHANCES) project

Diewertje Sluik $^{1}$, Nicole Jankovic ${ }^{1,2}$, Maria Hughes ${ }^{3}$, Mark G. O’Doherty ${ }^{3}$, Ben Schöttker ${ }^{4,5}$, Wojciech Drygas $^{6}$, Olov Rolandsson ${ }^{7}$, Satu Männistö ${ }^{8}$, José M. Ordóñez-Mena ${ }^{4,9,10}$, Jean Ferrieres $^{11}$, Christina Bamia ${ }^{12,13}$, Giovanni de Gaetano ${ }^{14}$, Jessica C. Kiefte-De Jong ${ }^{15,16}$, Oscar H. Franco ${ }^{16}$, Ivonne Sluijs ${ }^{17}$, Annemieke M.W. Spijkerman ${ }^{18}, \operatorname{Susana}_{\text {Sans }}{ }^{19}$, Sture Eriksson ${ }^{7}$, Daan Kromhout $^{1}$, Antonia Trichopoulou ${ }^{12,20}$, Tom Wilsgaard ${ }^{21}$, Herman Brenner ${ }^{4,9}$, Kari Kuulasmaa $^{8}$, Tiina Laatikainen ${ }^{8,22,23}$, Stefan Söderberg ${ }^{24}$, Licia Iacoviello ${ }^{14}$, Paolo Boffetta $^{12,25}$, Frank Kee ${ }^{3}$, Edith J.M. Feskens ${ }^{1}$

${ }^{1}$ Division of Human Nutrition, Wageningen University, Wageningen, the Netherlands;

${ }^{2}$ Centre of Clinical Epidemiology, Institute for Medical Informatics, Biometry and Epidemiology, Faculty of Medicine, University Duisburg-Essen, Germany; ${ }^{3}$ UKCRC Centre of Excellence for Public Health, School of Medicine, Dentistry, and Biomedical Sciences, Queen's University Belfast, Belfast, Northern Ireland; ${ }^{4}$ Division of Clinical Epidemiology and Aging Research, German Cancer Research Center (DKFZ), Heidelberg, Germany; ${ }^{5}$ Institute of Health Care and Social Sciences, FOM University, Essen, Germany; ${ }^{6}$ Department of Epidemiology, CVD Prevention and Health Promotion, Institute of Cardiology , Warsaw, Poland; ${ }^{7}$ Department of Public Health and Clinical Medicine, Family Medicine, Umeå University, Umeå, Sweden; ${ }^{8}$ Department of Health, National Institute for Health and Welfare (THL), Helsinki, Finland; ${ }^{9}$ Network of Aging Research (NAR), Heidelberg University, Heidelberg, Germany; ${ }^{10}$ Nuffield Department of Primary Care and Health Sciences, University of Oxford, Oxford, United Kingdom; ${ }^{11}$ Department of 
Cardiology, Toulouse University School of Medicine, Toulouse, France; ${ }^{12}$ Hellenic Health Foundation, Athens, Greece; ${ }^{13}$ Department of Hygiene, Epidemiology and Medical Statistics, University of Athens Medical School, Athens, Greece; ${ }^{14}$ Department of Epidemiology and Prevention. IRCCS Istituto Neurologico Mediterraneo Neuromed, Pozzilli, Italy; ${ }^{15}$ Global Public Health, Leiden University College, the Hague, the Netherlands; ${ }^{16}$ Department of Epidemiology, Erasmus Medical Center, Rotterdam, the Netherlands; ${ }^{17}$ Julius Center for Health Sciences and Primary Care, University Medical Center Utrecht, Utrecht, the Netherlands; ${ }^{18}$ National Institute for Public Health and the Environment (RIVM), Bilthoven, the Netherlands; ${ }^{19}$ Catalan Department of Health, Barcelona, Spain; ${ }^{20}$ WHO Collaborating Center for Nutrition and Health, Unit of Nutritional Epidemiology and Nutrition in Public Health, Department of Hygiene, Epidemiology and Medical Statistics, University of Athens Medical School, Athens, Greece; ${ }^{21}$ Department of Community Medicine, UiT the Arctic University of Norway, Tromsø, Norway; ${ }^{22}$ Institute of Public Health and Clinical Nutrition, University of Eastern Finland, Kuopio, Finland; ${ }^{23}$ Hospital District of North Karelia, Finland; ${ }^{24}$ Department of Public Health and Clinical Medicine, Cardiology and Heart Centre, Umeå University, Umeå, Sweden; ${ }^{25}$ Icahn School of Medicine, Mount Sinai School of Medicine, New York, USA.

\section{Correspondence and offprint requests to:}

Diewertje Sluik, DrPH

E-mail: Diewertje.Sluik@wur.nl

P.O. Box 17

6700 AA Wageningen

The Netherlands

Phone: +31 317485953 / Fax: +31 317482782 
51 Funding: The research of DS was supported by the Dutch Beer Institute and the European Foundation for Alcohol Research (ERAB). The sponsor did not have any role in the design and conduct of the study; collection, management, analysis and interpretation of the data; and preparation, review or approval of the manuscript. All authors declare no conflicts of interest. Running head: Alcoholic beverage preference and diabetes in Europe Abbreviations: Body Mass Index (BMI); coronary heart disease (CHD); confidence Interval (CI); the Consortium on Health and Ageing: Network of Cohorts in Europe and the United States (CHANCES); European Prospective Investigation into Cancer and Nutrition (EPIC); the Epidemiological Study on Chances for Prevention, Early Detection, and Optimized THERapy of Chronic Diseases at Old Age (ESTHER); Hazard Ratio (HR); MOnica Risk, 


\section{Abstract}

Background/Objectives: It is unknown if wine, beer, and spirit intake lead to a similar association with diabetes. We studied the association between alcoholic beverage preference and type 2 diabetes incidence in persons who reported to consume alcohol.

Subjects/Methods: Ten European cohort studies from the Consortium on Health and Ageing: Network of Cohorts in Europe and the United States (CHANCES) were included, comprising participant data of 62458 adults who reported alcohol consumption at baseline. Diabetes incidence was based on documented and/or self-reported diagnosis during follow-up. Preference was defined as $\geq 70 \%$ of total alcohol consumed was either beer, wine or spirits. Adjusted hazard ratios (HRs) were computed using Cox proportional hazard regression. Single cohort HRs were pooled by random-effects meta-analysis.

Results: Beer, wine, or spirit preference was not related to diabetes risk compared with having no preference. The pooled HRs were HR $1.06(95 \% \mathrm{CI} 0.93,1.20)$ for beer, HR 0.99 (95\%CI $0.88,1.11)$ for wine, and $\operatorname{HR} 1.19(95 \% \mathrm{CI} 0.97,1.46)$ for spirit preference. Absolute wine intake, adjusted for total alcohol, was associated with a lower diabetes risk: pooled HR per 6 grams/day was $0.96(95 \% \mathrm{CI} 0.93,0.99)$. A spirit preference was related to a higher diabetes risk in those with a higher BMI, in men and women separately, but not after excluding persons with prevalent diseases

Conclusions: This large individual-level meta-analysis among persons who reported alcohol consumption revealed that the preference for beer, wine, and spirits was similarly associated with diabetes incidence compared with having no preference. 


\section{Introduction}

Diabetes mellitus is the fourth to fifth leading cause of death in most high-income countries ${ }^{1}$. In 2014, the International Diabetes Federation estimated the prevalence at $7.9 \%$ in Europe ${ }^{1}$. Two systematic reviews and meta-analyses, including 20 and 26 cohort studies each, revealed a non-linear U-shaped relationship between alcohol consumption and type 2 diabetes incidence in both men and women ${ }^{2,3}$. The protective effect of alcohol consumption was largest with light to moderate consumption. Higher levels of ethanol consumption were not associated with diabetes or were associated with a higher $\operatorname{risk}^{2,3}$. On the other hand, a more recent meta-analysis of 38 studies concluded these risk reductions might have been overestimated by including less healthy former consumers in the reference group ${ }^{4}$. Moreover, the protective association might be confined to women and non-Asian populations only ${ }^{4}$.

Further research has indicated that the associations between alcohol and diabetes might be beverage-specific. A recent systematic review and meta-analysis of 13 prospective studies showed a strong protective association for wine consumption and type 2 diabetes, while for beer or spirits only a slight trend of a protective association was observed ${ }^{5}$. Within the European Prospective Investigation into Cancer and Nutrition (EPIC)-InterAct Study, moderate alcohol consumption was also related to a lower diabetes risk, in particular the consumption of red wine ${ }^{6}$. It was suggested that the association between alcohol and diabetes was likely to be explained by ethanol itself. Indeed, intervention studies have shown that alcohol increases levels of HDL-cholesterol, apoliprotein A1, and adiponectin, and reduces fibrinogen, fasting insulin and $\mathrm{HbA}_{1 c}$ concentrations ${ }^{7,8}$. Hence, the observed differences in association between wine, beer, and spirits and health outcomes might be due to sociodemographic and lifestyle factors associated with the preference and consumption of these beverages $^{9,10}$. However, differential effects of beer and wine on the glycemic response, as 
expressed by their glycemic index, have also been observed. Beer induces a higher glucose response than wine, which may be related to the development of diabetes ${ }^{11,12}$. Furthermore, due to its higher polyphenol content, red wine may exert additional benefits including reduction of blood pressure and inflammation and improving endothelial function ${ }^{13}$.

Alcohol consumption is a complex exposure that can be characterized in different ways: the absolute amount, the drinking frequency, and the beverage type. It is statistically difficult to distinguish between the overall alcohol effect and the specific effects of beer, wine, and spirits in observational studies ${ }^{14}$. We aimed to disentangle beverage-specific effects, independent of those from the absolute ethanol consumption, by studying the association between alcoholic beverage consumption and preference and type 2 diabetes incidence. This was done by performing a meta-analysis of harmonized individual participant data from several European cohorts including a large proportion of elderly participants. Because this study focused on the type of alcoholic beverage, the analyses were restricted to persons who reported alcohol consumption. Moreover, because the consumption of wine, beer, or spirits is mainly determined by factors including age, sex, socio-economic status, country, and lifestyle, these variables will be taken as much as possible into account in the analyses to strengthen potentially causal inference.

\section{Subjects and methods}

\section{Study design and population}

The Consortium on Health and Ageing: Network of Cohorts in Europe and the United States (CHANCES) project is a coordinated multi-country study which aims to harmonize data from ongoing prospective cohort studies in Europe and the USA in order to produce evidence on 
ageing-related health characteristics and on determinants of healthy ageing among the elderly in these countries ${ }^{15}$.

The CHANCES project includes cohorts from 14 studies across Europe and the USA. In most CHANCES cohorts, elderly are defined as those who were 60 years or older at recruitment. The CHANCES project as a whole has received ethical approval by the Hellenic Health Foundation Committee on Bioethics (HHFCB). In the individual cohorts, all participants signed informed consent for the original studies. The authors of this study did not have any access to personal information regarding the participants included in this paper. All data that have been analyzed are based on the CHANCES harmonized variables and are completely anonymized. For the present study, the following ten European cohorts were eligible for analysis: the Zutphen Elderly Study (the Netherlands) ${ }^{16}$, Rotterdam Study (the Netherlands) ${ }^{17}$, the study centers in the Netherlands, Greece, and Sweden from the European Prospective Investigation into Cancer and Nutrition (EPIC) - Elderly study ${ }^{18}$, the Tromsø Study (Norway) ${ }^{19}$, the Epidemiological Study on Chances for Prevention, Early Detection, and Optimized THERapy of Chronic Diseases at Old Age (ESTHER) study (Germany) ${ }^{20}$, and from the MOnica Risk, Genetics, Archiving and Monograph (MORGAM) study, the cohorts of FINRISK (Finland), Northern Sweden (Sweden), and MOLI-SANI (Italy) ${ }^{21,22}$. An extensive overview of the cohorts included in the CHANCES project and data assessment has been published elsewhere ${ }^{23}$. Table 1 displays the main characteristics of the included ten cohorts and participants.

Within the cohorts that were eligible for the present study, analyses were conducted upon all subjects who reported to consume alcohol, without any missing data on alcohol and followed up for diabetes incidence. Subjects with self-reported or independently ascertained prevalent 
diabetes at baseline or with missing information on prevalent diabetes at baseline were excluded from analysis. Supplemental Figure 1 shows the participant flow-charts of the ten included cohorts, comprising a total sample size of 63458 .

\section{Data assessment and harmonization}

Data in the CHANCES project have been collected within the framework of independent cohort studies, with different protocols for data collection and distinct original research foci. Data harmonization was a major task of the project and the data harmonization and conversion rules of the CHANCES project have been described elsewhere ${ }^{23}$.

\section{Alcoholic consumption and beverage preference}

Baseline alcohol data were recorded either by self-administered or interview-based questionnaires. The EPIC-Elderly and Rotterdam Study applied a validated food frequency questionnaire (FFQ) $)^{17,24,25}$ to assess alcohol intake. The Zutphen Elderly Study used a validated dietary history method to assess diet including alcohol ${ }^{16}$. The Tromsø Study, the ESTHER study, and MORGAM cohorts derived alcohol consumption from a general questionnaire. In the FINRISK Study, alcohol consumption during the previous week was assessed. If not already defined, average daily alcohol consumption in grams was estimated by adding the amounts of ethanol found in each standard drink or cohort specific size for beer, wine, and spirits. To ensure comparability across cohorts, a conversion rule was applied using standardized portion sizes $(330 \mathrm{ml}$ for a bottle of beer, $175 \mathrm{ml}$ for a glass of wine, and $25 \mathrm{ml}$ for a shot of spirit) and alcohol percentages in beer (4.5\%), wine (12\%), and spirits $(37.5 \%)$.

As defined in previous studies, a person was classified as having a preference for beer, wine, or spirits, when the alcohol consumption from the respective drink comprised $70 \%$ or more of 
the total alcohol consumption in grams per day. When the average alcohol consumption from beer, wine, or spirits did not add up to $70 \%$ of the total alcohol consumption, a person was classified as having no preference ${ }^{26,27}$. To assess robustness of this definition, a sensitivity analysis was performed using a cut-off of $50 \%$. Associations between the preference for beer, wine, or spirits and diabetes incidence compared to having no specific preference was assessed. Non-consumers, comprising never and former consumers, were not included in the analyses.

Next, the association between average daily intake from beer, wine, and spirits and diabetes incidence was studied. The absolute intakes of beer, wine, and spirits were adjusted for total alcohol consumption by the residual method ${ }^{27}$. In this procedure, intakes of the respective beverage were regressed upon their total alcohol consumption and the residuals from the regression were used in the analysis. These residuals represent the differences between each individual's actual intake and the intake predicted by their total alcohol consumption. Because residuals, by definition, have a mean of zero, a constant representing the mean intake in each population was added to every value to reflect actual consumption values ${ }^{28}$. The beer, wine, and spirit residuals are uncorrelated with total alcohol consumption and this allows variation due to the intake of beer, wine, and spirits to be evaluated directly. The beer, wine, and spirit residuals were analyzed in tertiles and per $6 \mathrm{~g} /$ day.

Information on drinking patterns, i.e. consumption frequency, was not available for all cohorts. Sensitivity analyses were performed adjusting the associations additionally for frequency of consumption (less than once a week, 1-2 days/week, 3-5 days/week, or 6-7 days/week) in the Tromsø Study, ESTHER, and MORGAM. 


\section{Diabetes ascertainment}

Diabetes incidence was based on documented or self-reported type 2 diabetes during followup or based on fasting glucose measures, depending on the available options within the cohorts shown in Table 1.

\section{Covariate assessment}

Socio-demographic, lifestyle, and disease history data were assessed by self-administered questionnaires or in interviews. Weight and height were either measured or self-reported, and blood samples were drawn to determine total and HDL cholesterol. Diet quality was assessed with the Healthy Diet Indicator (HDI) as developed by Jankovic et al. ${ }^{29}$. The HDI score reflects adherence to the $2003 \mathrm{WHO}$ dietary guidelines. The score ranges from 0 to 70 points and includes 6 nutrients (saturated fatty acids, polyunsaturated fatty acids, mono- and disaccharides, protein, cholesterol, dietary fiber) and 1 food group (fruit and vegetables) of the 14 WHO guideline goals, which were available for the cohorts providing nutrition data ${ }^{29}$. Dietary intake data to calculate the HDI score were available for the Zutphen Elderly Study, Rotterdam Study, and EPIC-Elderly. Self-reported physical activity was assessed by questionnaires in the Zutphen Elderly Study, Rotterdam Study, EPIC-Elderly the Netherlands and Greece, and ESTHER.

\section{Statistical analysis}

The statistical analyses were performed using SAS, version 9.3, software (SAS Institute, Inc., Cary, North Carolina). Hazard Ratios (HRs) and 95\% confidence intervals (CIs) for diabetes were calculated using Cox proportional hazard regression. The proportional hazard assumption was tested and not violated. Missing values for any of the covariates were imputed using the multiple imputation method, in which all variables included in the 
statistical models were included in the procedure. For each cohort, five duplicate datasets were produced and after statistical inference on the duplicate datasets, pooled estimates were calculated with PROC MIANALYZE ${ }^{30}$. In Model 1, HRs were adjusted for sociodemographic factors: age (continuous; years), gender (not applicable for the Zutphen Elderly Study, which is composed only of men), education (categorical: primary or less (low), more than primary but less than college or university (middle), college or university (high)), employment status (categorical: full-time or part-time employment and not of pensionable age, self-employed, housewife and not of pensionable age, pensionable age and still working, pensionable age and not working, stopped work before retirement age due to poor health, unemployed and not of pensionable age; not applicable for SENECA and the Zutphen Elderly Study, where only retired subjects are included), and prevalent coronary heart disease (CHD; yes/no) or cancer (yes/no). Model 2 was additionally adjusted for the lifestyle factors: smoking status (categorical: never, former, current), sports activity (continuous: hours per week; physical activity data were not available for EPIC-Elderly Sweden, the Tromsø Study, and MORGAM; total physical activity was used in the Rotterdam Study), and HDI-score (continuous; dietary intake data to generate the HDI score was not available for ESTHER, the Tromsø Study, and MORGAM).

Because the definition of alcoholic beverage preference is not based upon absolute alcohol consumption, persons with a beer preference might, for instance, have a higher absolute alcohol intake than persons with a wine preference. Thus, total alcohol consumption might be a confounding factor. Due to the U-shaped relationship between total alcohol and diabetes ${ }^{2,3}$, additional adjustment for absolute alcohol consumption (gram/day) was evaluated using fractional polynomials where the best fit regression model was selected with the SAS Macro "Multivariable Fractional Polynomials"31. This macro uses an algorithm to determines the 
inclusion and transformation of continuous covariates while taking into account their nonlinearity. In a stepwise approach, the algorithm constructs a fractional polynomial transformation for the continuous covariate. Backward elimination selects the best transformation of the covariate, e.g. linear, first degree or second degree. Depending on the Pvalues associated with the best transformations, covariates may be eliminated from the model. In all cohorts, absolute alcohol consumption was omitted from the best fit model. Because the residuals of beer, wine, and spirit consumption are uncorrelated with total alcohol intake, these HR were not adjusted for total alcohol.

Adjustment model 3 was additionally adjusted for BMI (linearly or second degree; $\mathrm{kg} / \mathrm{m}^{2}$ ); this adjustment for BMI was also evaluated using fractional polynomials. BMI was omitted from the best fit model in the Zutphen Elderly Study, included as a second degree variable in ESTHER and FINRISK, and included linearly in the remaining cohorts. BMI is one of the most important risk factors for diabetes, but is also on a possible causal pathway between alcohol consumption and diabetes. Therefore, crude and adjusted BMI across alcoholic beverage preference categories was estimated with multiple linear regression. To investigate effect modification by BMI, stratified analyses were performed on persons with a BMI $<25$ and $\geq 25 \mathrm{~kg} / \mathrm{m}^{2}$ and the P-value for interaction was checked after including a product term in the regression models. Furthermore, stratified analyses were performed for men and women separately to check for potential effect modification. Finally, subjects with prevalent CHD or cancer at baseline or a follow-up less than 2 years were excluded in a sensitivity analysis.

Cohort-specific HR estimates and 95\% CIs for diabetes incidence from having a beer, wine, or spirit preference compared with no preference and for a beer, wine, or spirit consumption (per 6 gram/day) were pooled in meta-analyses, using adjustment model 3. Inverse variance 
weighting was applied to give the largest weight to the study with the lowest variance. The random-effects model takes into account the between-study variance and the within-study variance. Heterogeneity between studies was assessed by the Q statistic and the $\mathrm{I}^{2}$ index. $\mathrm{I}^{2}$ was calculated as $\mathrm{I}^{2}=((\mathrm{Q}-\mathrm{df}) / \mathrm{Q}) * 100$, where “df” stands for degrees of freedom, i.e. total number of studies $(\mathrm{k})$ minus 1 . Random-effects meta-analyses with inverse variance weighting were performed using the R package "meta" (R version 3.3.1). Statistical tests were two-sided and P-values $<0.05$ were considered statistically significant.

\section{Results}

In most cohorts, persons with a wine preference constituted the largest group, ranging from 44\% in ESTHER (Germany) to 79\% in MOLI-SANI (Italy) (Supplemental Table 1). In EPIC-Elderly Sweden, the Tromsø Study, FINRISK, and Northern-Sweden persons with no preference formed the largest group and in the Zutphen Elderly Study (the Netherlands), persons with a spirit preference comprised the largest group, i.e. $62 \%$. Across all cohorts, those who preferred wine were relatively more highly educated and were more likely to be a never smoker, and female. Furthermore, those with a beer or spirit preference were more likely to be male and current smoker. Persons with no specific preference generally had the highest absolute alcohol consumption. After adjustment for age, sex, education, employment, prevalent diseases, smoking, alcohol, sports activity, diet, BMI was lowest among those with a beer or wine preference and BMI was highest among persons with a spirit preference (Supplemental Table 1).

The pooled HRs from the random-effects meta-analyses showed no significant association between having a preference for beer, wine, or spirits and diabetes incidence compared with having no specific preference after adjustment for age, sex, education, prevalent diseases, 
lifestyle factors, and BMI (Figure 1-3). Pooled HR was 1.06 (95\%CI 0.93, 1.20) for a beer preference, HR $0.99(95 \%$ CI 0.88, 1.11) for a wine preference, and HR 1.19 (95\%CI 0.97, 1.46) for having a spirit preference. Based on the $I^{2}$ index and the Q-statistic, between-study heterogeneity was observed for the effect estimates of having a spirit preference.

Separate HRs and 95\% CIs for the associations between a beer, wine, or spirits and diabetes incidence according to the different levels of adjustment are shown in Supplemental Table 1. Compared with persons with no preference, a preference for beer, wine, or spirits was in most cohorts not significantly associated with diabetes incidence. In the Rotterdam Study, beer or spirit preference had a significant association with a higher diabetes incidence. In EPICElderly Greece, having a wine preference tended to be associated with a lower diabetes incidence. Within the cohorts, additional adjustment for BMI (Model 3) had mixed, but small effects on the observed associations.

The pooled HR for the association between alcohol preference and incident diabetes among sub-groups and with additional adjustments are shown in Table 2. Diabetes risk among persons with a spirit preference was higher in those with a higher BMI, in men and in women, but not after excluding persons with prevalent diseases. Excluding persons with prevalent diseases yielded similar results to the findings including those persons. P-values for interaction by BMI were not significant for all cohorts and did not therefore give indication for effect modification. Furthermore, additional adjustment for consumption frequency and alternative analysis using 50\% as a cut-off in the definition of preference showed similar associations. 
Additionally, the association between the residuals of beer, wine, and spirit intake per 6 gram/day and diabetes incidence was assessed (Figure 4-6). Pooled HR was 1.03 (95\%CI $0.99,1.06)$ per 6 grams of beer intake, HR $0.96(95 \%$ CI $0.93,0.99)$ per 6 grams of wine intake, and HR $1.02(95 \%$ CI 0.98, 1.06) per 6 grams of spirit intake. Cohort-specific HR according to tertiles and per 6 grams/day generally showed similar associations

\section{(Supplemental Table 2).}

\section{Discussion}

This meta-analysis of individual participant data from ten prospective European cohorts comprising $\sim 60,000$ adults who reported at least some alcohol consumption showed that a preference for beer, wine or spirits was not associated with a lower or higher diabetes risk compared with having no specific preference, taking into account several socio-demographic and lifestyle variables.

\section{To our knowledge, no other studies have investigated the association between alcoholic} beverage preference and diabetes risk. However, a number of observational studies have assessed associations of absolute beverage-specific consumption and diabetes, showing inconsistent results. Among 36,527 Australian adults, Hodge et al. observed an inverse association between wine consumption and risk of type 2 diabetes, but not for beer or spirits ${ }^{32}$. In the EPIC-InterAct Study, a prospective case-cohort study of 16,154 participants and 12,403 incident diabetes cases, consumption of wine and fortified wine were most strongly related with a reduced diabetes risk ${ }^{6}$. Moreover, compared with a light consumption, men who did not consume beer had a reduced risk of diabetes in the EPIC-InterAct Study: HR 0.84 (95\%CI $0.74,0.95)$ and in women higher spirit consumption was associated with an higher diabetes risk (P-trend 0.044). Fagherazzi et al. observed an inverse association between wine 
consumption and diabetes risk when compared to other types of alcoholic beverage among 66,485 women from the French E3N-EPIC cohort $^{33}$. In contrast, Conigrave et al., did not find a protective effect of red wine on diabetes risk among 46,892 U.S. male health professionals, whereas inverse associations for beer, spirits and white wine were similar and independent ${ }^{34}$. Moreover, two other studies in large U.S. cohorts also did not observe a specific protective effect of wine consumption on diabetes risk compared with beer or spirit consumption ${ }^{35,36}$. In their meta-analysis of 13 prospective studies, Huang, Wang, and Zhang presented a pooled RR of 0.85 (95\% CI 0.80-0.89) for wine consumption, and RR 0.96 (95\% CI 0.92, 1.00) for beer consumption and RR 0.95 (95\%CI 0.89-1.03) for spirit consumption and type 2 diabetes risk compared to no or rare alcohol consumption ${ }^{5}$. In the present study, the pooled HR for residuals of beer, wine, and spirit intake showed similar results: a higher wine intake was related to a lower diabetes risk, even after fully taking into account total alcohol consumption. This further confirms the consistent finding that constituents other than ethanol in red wine may exert additional health benefits ${ }^{13}$.

Several other studies have found differential effects for the type of alcoholic beverage and diabetes risk, with a stronger beneficial association for wine consumption compared to abstinence. These observations could either be explained by a true beneficial effect of wine compared with beer and spirits, or by an artefact arising from residual confounding. Firstly, a true differential effect for beer, wine, and spirits and diabetes incidence might be caused by beneficial compounds other than ethanol in particular those found in wine. For example, a randomized controlled cross-over trial in 67 men at high cardiovascular risk showed that red wine rich in polyphenols with or without alcohol improved glucose metabolism ${ }^{37}$. This was not confirmed in our study, where we have found no additional beneficial association for having a wine preference compared to having no preference. Secondly, the observation might 
be an artefact caused by confounding factors associated with the type of alcoholic beverage consumed. Indeed, the choice of alcoholic beverage is associated with a wide range of cultural, socio-demographic and lifestyle factors ${ }^{9}, 38$, which may confound the association between alcohol and diabetes risk. Moreover, other important determinants of diabetes risk including age, gender, smoking status and overall drinking patterns differ across alcoholic beverage preference and study populations ${ }^{10}$. Therefore, we have adjusted the associations for age, gender, socio-economic status, and lifestyle factors including absolute alcohol consumption and BMI. However, we cannot exclude any residual confounding as a result of unmeasured or imprecisely measured confounders. Lastly, in previous studies there is a tendency to find an association for the alcoholic beverage that is most consumed. In the above mentioned studies into beverage type and diabetes risk, most of the alcohol was consumed as wine $^{6,32,33}$. In our study, ten cohorts from seven European countries were included with varying preferences, suggesting this might have less influence on our findings and provided a wider insight into alcohol preference across Europe.

We observed a tendency toward a higher diabetes risk among persons with a spirit preference compared to those having no specific preference among men and women when analyzed separately and those with a higher BMI. This was also seen within EPIC-InterAct ${ }^{6}$. Crosssectional studies have shown that a spirit preference is associated with an unhealthier lifestyle: persons who preferred spirits have been shown to have a higher BMI, are more likely to be smokers, and display unhealthier diet. Furthermore, spirits may be more often used for heavy binge drinking compared to wine ${ }^{9,10}$. In the present study, we could only take consumption frequency into account in a subset of five cohorts. Furthermore, the association was attenuated when excluding persons with prevalent diseases or a short follow-up, indicating that some 
degree of reverse causation might be present. Finally, we were not able to take diet and physical activity into account in all cohorts.

To avoid any bias by the inclusion of former drinkers, the current analysis was restricted to persons who reported some alcohol consumption. Furthermore, persons with no specific preference, i.e. mixed drinkers, were used as a reference. Most other observational studies have used non-consumers as a reference; however, this has been contested. Non-consumers are in general a heterogeneous group comprising lifetime abstainers and former drinkers. In many high-income countries, lifetime abstinence of alcohol is not normative and this group differs from alcohol consumers in other health determinants ${ }^{39}$. Moreover, former drinkers may have quit because of ill health arising from their former (heavy) alcohol use. As a result, these individuals are more vulnerable for morbidity and mortality and their ill health may confound the association between alcohol consumption and health outcomes. Using non-consumers as a reference group may overestimate the beneficial effects of alcohol ${ }^{40}$. On the other hand, in the meta-analysis of Di Castelnuovo et al., there was still a protective effect of alcohol consumption in the general population after exclusion of former drinkers ${ }^{41}$. We were unable to take into account former alcohol consumption in all cohorts, but by restricting the analyses to alcohol consumers, possible confounding by abstinence or former alcohol consumption could not influence our results.

The association between alcoholic beverage preference and diabetes may be partly driven by obesity: since adiposity is on one causal pathway between absolute alcohol consumption and diabetes, adjusting for BMI may lead to overadjustment bias ${ }^{42}$. However, after multiple adjustments, those with a spirit preference had the highest BMI and persons with a beer or wine preference had the lowest BMI. Because BMI is a strong risk factor for developing 
diabetes, the effect of moderate alcohol consumption might be strongest, in absolute terms, in those at higher risk. In our analysis, the association between spirit preference and diabetes incidence was higher among those with overweight or obese (BMI $\left.>25 \mathrm{~kg} / \mathrm{m}^{2}\right)$. In contrast, Beulens et al. found that moderate alcohol consumption was more strongly related to a reduced diabetes risk in overweight men and women than in their normal weight counterparts $^{6}$. Moreover, in the French E3N-EPIC cohort, overweight women consuming two or more glasses of wine per day had a lower diabetes risk, whereas in normal weight women consuming the same amount, no association was observed ${ }^{33}$.

We aimed to disentangle beverage-specific effects, independent of those from the absolute ethanol consumption, by studying the association between alcoholic beverage preference and type 2 diabetes incidence. Beverage preference was used to classify the study population according to their alcohol intake. This approach of studying preference rather than absolute intake can thus be considered as a qualitative approach. Independent from the biological mechanisms associated with the chemical composition of the beverages, beverage preference per se may not be directly associated with diabetes incidence. Therefore, we have additionally studied the residuals of beer, wine and spirit intake, fully adjusted for total alcohol consumption by the residual method ${ }^{28}$; these analyses yielded similar findings. The number of cases distributed by beverage preference differed across the cohorts and were in some cohorts quite low, which may have affected the statistical power of the analyses. Non-consumers were excluded from the analysis to prevent non-consumers and former (heavy) consumers to affect the results. As a result, these findings only apply to alcohol consumers.

\section{The CHANCES project is a large-scale multi-national collaboration of cohort studies} including a large number of elderly persons. Pooled analyses of the individual participant data 
from the different cohorts is a cost-efficient analytical approach and increases statistical power considerably. However, we had to rely on secondary data collected according to different study objectives and protocols, which may be a weakness ${ }^{15}$. With respect to type 2 diabetes incidence, the identification and verification of diabetes cases varied across the cohorts. The oral glucose tolerance test is considered the gold standard of diabetes ascertainment, but recently fasting glucose has been shown to be the most accurate method of diabetes diagnosis ${ }^{43}$. Most cohort studies relied on self-reports, linkage with registries, $\mathrm{HbA}_{1 \mathrm{c}}$, or fasting blood glucose measures. As a result, misclassification could have been present and we might have underestimated the number of diabetes cases. However, only if this misclassification is differential and related to alcohol preference, would it have influenced the direction of the effect estimates, and yet our observed associations across cohorts were broadly consistent. Furthermore, it is difficult to distinguish between type 1 and type 2 diabetes; therefore, some cohorts may not have been able to appropriately distinguish between the types. Moreover, this issue is not restricted to this study only. Diagnosing diabetes can be equivocal: the clinical diagnosis is based on a pre-specified cut-off point on a continuous scale of declining glycemic control, but clinical practice will dictate how assiduously the necessary tests are applied. Furthermore, the diagnosis is often based on the occurrence of complications of the disease and the disease can remain asymptomatic for years. Hence, it has been estimated that up to $50 \%$ of all type 2 diabetes patients are undiagnosed ${ }^{44}$. As a result, the true association may have been underestimated.

This meta-analysis of individual participant data from ten cohorts among Europeans who reported at least some alcohol consumption showed that beer, wine, and spirits were similarly associated with diabetes incidence. The recommendations of the American Diabetes Association for the prevention of diabetes suggest that if adults choose to drink alcohol, daily 
intake should be limited to a moderate amount, i.e. no more than one drink per day for women and two drinks per day for men ${ }^{45}$. Our analysis offers little support for making beverage specific recommendation for diabetes prevention.

\section{Acknowledgements}

The research of DS was supported by the Dutch Beer Institute and the European Foundation for Alcohol Research (ERAB). The sponsor did not have any role in the design and conduct of the study; collection, management, analysis and interpretation of the data; and preparation, review or approval of the manuscript. No other authors declare conflicts of interest.

This analysis was part of the Consortium on Health and Ageing (CHANCES) project funded in the FP7 framework programme of the Directorate-General for Research \& Innovation in the European Commission (grant 242244). The CHANCES project is coordinated by the Hellenic Health Foundation, Greece. Harmonization of the data from the MORGAM cohorts was also supported by European Union FP 7 project BiomarCaRE (278913).

DS, FK, EJMF designed the study and formulated the research question; OHF, DK, AT, TW, HB, KK, TL, SS, LI, and PB acquired the data and contributed reagents/materials/analysis tools; DS carried out the study, analyzed the data, and drafted the manuscript; All authors critically revised the manuscript for important intellectual content and approved of the final version to be published.

\section{References}

1. International Diabetes Federation. IDF Diabetes Atlas, Sixth Edition [Retrieved 12 March 2015]. Available from: http://www.idf.org/diabetesatlas 2014. 
2. Li XH, Yu FF, Zhou YH, He J. Association between alcohol consumption and the risk of incident type 2 diabetes: a systematic review and dose-response meta-analysis. The American journal of clinical nutrition 2016; 103(3): 818-829. e-pub ahead of print 2016/02/05; doi: 10.3945/ajcn.115.114389

3. Baliunas DO, Taylor BJ, Irving H, Roerecke M, Patra J, Mohapatra S et al. Alcohol as a risk factor for type 2 diabetes: A systematic review and meta-analysis. Diabetes care 2009; 32(11): 2123-2132. e-pub ahead of print 2009/10/31; doi: 10.2337/dc09-0227

4. Knott C, Bell S, Britton A. Alcohol Consumption and the Risk of Type 2 Diabetes: A Systematic Review and Dose-Response Meta-analysis of More Than 1.9 Million Individuals From 38 Observational Studies. Diabetes care 2015; 38(9): 1804-1812. epub ahead of print 2015/08/22; doi: 10.2337/dc15-0710

5. Huang J, Wang X, Zhang Y. Specific Types of Alcoholic Beverage Consumption and Risk of Type 2 Diabetes: A Systematic Review and Meta-analysis. Journal of diabetes investigation 2016. e-pub ahead of print 2016/05/18; doi: 10.1111/jdi.12537

6. Beulens JW, van der Schouw YT, Bergmann MM, Rohrmann S, Schulze MB, Buijsse B et al. Alcohol consumption and risk of type 2 diabetes in European men and women: influence of beverage type and body size The EPIC-InterAct study. Journal of internal medicine 2012; 272(4): 358-370. e-pub ahead of print 2012/02/23; doi: $10.1111 / j .1365-2796.2012 .02532 . x$

7. Brien SE, Ronksley PE, Turner BJ, Mukamal KJ, Ghali WA. Effect of alcohol consumption on biological markers associated with risk of coronary heart disease: systematic review and meta-analysis of interventional studies. Bmj 2011; 342: d636. epub ahead of print 2011/02/24; doi: 10.1136/bmj.d636

8. Schrieks IC, Heil AL, Hendriks HF, Mukamal KJ, Beulens JW. The effect of alcohol consumption on insulin sensitivity and glycemic status: a systematic review and meta- 
analysis of intervention studies. Diabetes care 2015; 38(4): 723-732. e-pub ahead of print 2015/03/26; doi: 10.2337/dc14-1556

9. Gronbaek M. Confounders of the relation between type of alcohol and cardiovascular disease. Annals of Epidemiology 2007; 17(5): S13-S15. doi:

10.1016/j.annepidem.2007.01.004

10. Sluik D, Bezemer R, Sierksma A, Feskens E. Alcoholic Beverage Preference and Dietary Habits: A Systematic Literature Review. Critical reviews in food science and nutrition 2015: 0. e-pub ahead of print 2015/02/13; doi:

$10.1080 / 10408398.2013 .841118$

11. Brand-Miller JC, Fatema K, Middlemiss C, Bare M, Liu V, Atkinson F et al. Effect of alcoholic beverages on postprandial glycemia and insulinemia in lean, young, healthy adults. The American journal of clinical nutrition 2007; 85(6): 1545-1551.

12. Hatonen KA, Virtamo J, Eriksson JG, Perala MM, Sinkko HK, Leiviska J et al. Modifying effects of alcohol on the postprandial glucose and insulin responses in healthy subjects. The American journal of clinical nutrition 2012; 96(1): 44-49. e-pub ahead of print 2012/06/01; doi: 10.3945/ajcn.111.031682

13. Arranz S, Chiva-Blanch G, Valderas-Martinez P, Medina-Remon A, LamuelaRaventos RM, Estruch R. Wine, beer, alcohol and polyphenols on cardiovascular disease and cancer. Nutrients 2012; 4(7): 759-781. e-pub ahead of print 2012/08/02; doi: $10.3390 /$ nu 4070759

14. Wacholder S, Schatzkin A, Freedman LS, Kipnis V, Hartman A, Brown CC. Can energy adjustment separate the effects of energy from those of specific macronutrients? American journal of epidemiology 1994; 140(9): 848-855.

15. Boffetta P, Bobak M, Borsch-Supan A, Brenner H, Eriksson S, Grodstein F et al. The Consortium on Health and Ageing: Network of Cohorts in Europe and the United 
States (CHANCES) project--design, population and data harmonization of a largescale, international study. European journal of epidemiology 2014; 29(12): 929-936. e-pub ahead of print 2014/12/17; doi: 10.1007/s10654-014-9977-1

16. Buijsse B, Feskens EJ, Kok FJ, Kromhout D. Cocoa intake, blood pressure, and cardiovascular mortality: the Zutphen Elderly Study. Archives of internal medicine 2006; 166(4): 411-417. e-pub ahead of print 2006/03/01; doi:

10.1001/archinte.166.4.411

17. Hofman A, Brusselle GG, Darwish Murad S, van Duijn CM, Franco OH, Goedegebure A et al. The Rotterdam Study: 2016 objectives and design update. European journal of epidemiology 2015; 30(8): 661-708. doi: 10.1007/s10654-0150082-X

18. Trichopoulou A, Orfanos P, Norat T, Bueno-de-Mesquita B, Ocke MC, Peeters PH et al. Modified Mediterranean diet and survival: EPIC-elderly prospective cohort study. Bmj 2005; 330(7498): 991. e-pub ahead of print 2005/04/12; doi:

\subsection{6/bmj.38415.644155.8F}

19. Jacobsen BK, Eggen AE, Mathiesen EB, Wilsgaard T, Njolstad I. Cohort profile: the Tromso Study. Int J Epidemiol 2012; 41(4): 961-967. e-pub ahead of print 2011/03/23; doi: 10.1093/ije/dyr049

20. Schottker B, Haug U, Schomburg L, Kohrle J, Perna L, Muller H et al. Strong associations of 25-hydroxyvitamin D concentrations with all-cause, cardiovascular, cancer, and respiratory disease mortality in a large cohort study. The American journal of clinical nutrition 2013; 97(4): 782-793. e-pub ahead of print 2013/03/01; doi: 10.3945/ajen.112.047712 
21. Evans A, Salomaa V, Kulathinal S, Asplund K, Cambien F, Ferrario M et al. MORGAM (an international pooling of cardiovascular cohorts). Int J Epidemiol 2005; 34(1): 21-27. e-pub ahead of print 2004/11/25; doi: 10.1093/ije/dyh327

22. Di Castelnuovo A, de Curtis A, Costanzo S, Persichillo M, Olivieri M, Zito F et al. Association of D-dimer levels with all-cause mortality in a healthy adult population: findings from the MOLI-SANI study. Haematologica 2013; 98(9): 1476-1480. e-pub ahead of print 2013/05/07; doi: 10.3324/haematol.2012.083410

23. Kuulasmaa K, Palosaari T, editors. Contributors from Partners of the Consortium on Health and Ageing: Network of Cohorts in Europe and the United States (CHANCES). CHANCES cohort descriptions, assessment of the availability and quality of data, and definitions of variables. MORGAM Project e-publications [Internet]. 2015; (6). URN:NBN:fi-fe201501151161. Available from URL:http://www.thl.fi/publications/morgam/chances d9/index.html. Available from: URL (Accessed $n$ Date Accessed Year)|.

24. Klipstein-Grobusch K, den Breeijen JH, Goldbohm RA, Geleijnse JM, Hofman A, Grobbee DE et al. Dietary assessment in the elderly: validation of a semiquantitative food frequency questionnaire. European journal of clinical nutrition 1998; 52(8): 588596. e-pub ahead of print 1998/09/02;

25. Riboli E, Kaaks R. The EPIC Project: rationale and study design. European Prospective Investigation into Cancer and Nutrition. Int J Epidemiol 1997; 26 Suppl 1: S6-14. e-pub ahead of print 1997/01/01;

26. Sluik D, van Lee L, Geelen A, Feskens EJ. Alcoholic beverage preference and diet in a representative Dutch population: the Dutch national food consumption survey 20072010. European journal of clinical nutrition 2014; 68(3): 287-294. e-pub ahead of print 2014/01/09; doi: 10.1038/ejen.2013.279 
27. Sluik D, Jankovic N, O'Doherty MG, Geelen A, Schottker B, Rolandsson O et al. Alcoholic Beverage Preference and Dietary Habits in Elderly across Europe: Analyses within the Consortium on Health and Ageing: Network of Cohorts in Europe and the United States (CHANCES) Project. PloS one 2016; 11(8): e0161603. e-pub ahead of print 2016/08/23; doi: 10.1371/journal.pone.0161603

28. Willett WC, Howe GR, Kushi LH. Adjustment for total energy intake in epidemiologic studies. The American journal of clinical nutrition 1997; 65(4 Suppl): 1220S-1228S; discussion 1229S-1231S. e-pub ahead of print 1997/04/01;

29. Jankovic N, Geelen A, Streppel MT, de Groot LC, Orfanos P, van den Hooven EH et al. Adherence to a healthy diet according to the World Health Organization guidelines and all-cause mortality in elderly adults from Europe and the United States. American journal of epidemiology 2014; 180(10): 978-988. e-pub ahead of print 2014/10/17; doi: 10.1093/aje/kwu229

30. Sterne JA, White IR, Carlin JB, Spratt M, Royston P, Kenward MG et al. Multiple imputation for missing data in epidemiological and clinical research: potential and pitfalls. Bmj 2009; 338: b2393. e-pub ahead of print 2009/07/01; doi: 10.1136/bmj.b2393

31. Sauerbrei W, Meier-Hirmer C, Benner A, Royston P. Multivariable regression model building by using fractional polynomials: Description of SAS, STATA, and R programs. Computational Statistics \& Data Analysis 2006; 50: 3464-3485.

32. Hodge AM, English DR, O'Dea K, Giles GG. Alcohol intake, consumption pattern and beverage type, and the risk of Type 2 diabetes. Diabetic medicine : a journal of the British Diabetic Association 2006; 23(6): 690-697. doi: 10.1111/j.14645491.2006.01864.x 
33. Fagherazzi G, Vilier A, Lajous M, Boutron-Ruault MC, Balkau B, Clavel-Chapelon F et al. Wine consumption throughout life is inversely associated with type 2 diabetes risk, but only in overweight individuals: results from a large female French cohort study. European journal of epidemiology 2014; 29(11): 831-839. doi: $10.1007 / \mathrm{s} 10654-014-9955-7$

34. Conigrave KM, Hu BF, Camargo CA, Jr., Stampfer MJ, Willett WC, Rimm EB. A prospective study of drinking patterns in relation to risk of type 2 diabetes among men. Diabetes 2001; 50(10): 2390-2395.

35. Kao WH, Puddey IB, Boland LL, Watson RL, Brancati FL. Alcohol consumption and the risk of type 2 diabetes mellitus: atherosclerosis risk in communities study. American journal of epidemiology 2001; 154(8): 748-757. e-pub ahead of print 2001/10/09;

36. Wannamethee SG, Camargo CA, Jr., Manson JE, Willett WC, Rimm EB. Alcohol drinking patterns and risk of type 2 diabetes mellitus among younger women. Archives of internal medicine 2003; 163(11): 1329-1336. e-pub ahead of print 2003/06/11; doi: 10.1001/archinte.163.11.1329

37. Chiva-Blanch G, Urpi-Sarda M, Ros E, Valderas-Martinez P, Casas R, Arranz S et al. Effects of red wine polyphenols and alcohol on glucose metabolism and the lipid profile: a randomized clinical trial. Clinical nutrition 2013; 32(2): 200-206. e-pub ahead of print 2012/09/25; doi: 10.1016/j.clnu.2012.08.022

38. Gronbaek M. Factors influencing the relation between alcohol and mortality--with focus on wine. Journal of internal medicine 2001; 250(4): 291-308. e-pub ahead of print 2001/09/29;

39. Rehm J, Irving H, Ye Y, Kerr WC, Bond J, Greenfield TK. Are lifetime abstainers the best control group in alcohol epidemiology? On the stability and validity of reported 
lifetime abstention. American journal of epidemiology 2008; 168(8): 866-871. e-pub ahead of print 2008/08/15; doi: 10.1093/aje/kwn093

40. Shaper AG, Wannamethee G, Walker M. Alcohol and mortality in British men: explaining the U-shaped curve. Lancet 1988; 2(8623): 1267-1273. e-pub ahead of print 1988/12/03;

41. Di Castelnuovo A, Costanzo S, Bagnardi V, Donati MB, Iacoviello L, de Gaetano G. Alcohol dosing and total mortality in men and women: an updated meta-analysis of 34 prospective studies. Archives of internal medicine 2006; 166(22): 2437-2445. e-pub ahead of print 2006/12/13; doi: 10.1001/archinte.166.22.2437

42. Schisterman EF, Cole SR, Platt RW. Overadjustment bias and unnecessary adjustment in epidemiologic studies. Epidemiology 2009; 20(4): 488-495. e-pub ahead of print 2009/06/16; doi: 10.1097/EDE.0b013e3181a819a1

43. Collaboration NCDRF. Effects of diabetes definition on global surveillance of diabetes prevalence and diagnosis: a pooled analysis of 96 population-based studies with 331288 participants. The lancet. Diabetes \& endocrinology 2015; 3(8): 624-637. e-pub ahead of print 2015/06/26; doi: 10.1016/S2213-8587(15)00129-1

44. Ryden L, Standl E, Bartnik M, Van den Berghe G, Betteridge J, de Boer MJ et al. Guidelines on diabetes, pre-diabetes, and cardiovascular diseases: executive summary. The Task Force on Diabetes and Cardiovascular Diseases of the European Society of Cardiology (ESC) and of the European Association for the Study of Diabetes (EASD). European heart journal 2007; 28(1): 88-136. e-pub ahead of print 2007/01/16; doi: 10.1093/eurheartj/ehl260

45. American Diabetes Association.Nutrition recommendations and interventions for diabetes: a position statement of the American Diabetes Association. Diabetes care 2008; 31 Suppl 1: S61-78. e-pub ahead of print 2008/01/10; doi: 10.2337/dc08-S061 
674 46. Feskens EJ, Loeber JG, Kromhout D. Diet and physical activity as determinants of hyperinsulinemia: the Zutphen Elderly Study. American journal of epidemiology. Aug

676 15 1994;140(4):350-360.

677 47. Beulens JW, Stolk RP, van der Schouw YT, Grobbee DE, Hendriks HF, Bots ML. Alcohol consumption and risk of type 2 diabetes among older women. Diabetes Care. Dec 2005;28(12):2933-2938.

48. Kulathinal S, Niemelä M, Niiranen T, Saarela O, Palosaari T, Tapanainen H, et al. Description of MORGAM Cohorts. MORGAM Project e-publications [Internet]. 2005-; (2). URN:NBN:fi-fe20051214. Available from URL: http://www.thl.fi/publications/morgam/cohorts/index.html. 
691

692

\section{Figure legends:}

Figure 1. Forest plot with pooled Hazard Ratios (HRs) and 95\% Confidence Intervals (CIs) for the association between beer preference and diabetes incidence compared to having no preference adjusted for age, sex, education, employment status, prevalent coronary heart disease and cancer, smoking status, physical activity (if available), Healthy Diet Indicator score (if available), and BMI.

Figure 2. Forest plot with pooled Hazard Ratios (HRs) and 95\% Confidence Intervals (CIs) for the association between wine preference and diabetes incidence compared to having no preference adjusted for age, sex, education, employment status, prevalent coronary heart disease and cancer, smoking status, physical activity (if available), Healthy Diet Indicator score (if available), and BMI.

Figure 3. Forest plot with pooled Hazard Ratios (HRs) and 95\% Confidence Intervals (CIs) for the association between spirit preference and diabetes incidence compared to having no preference adjusted for age, sex, education, employment status, prevalent coronary heart disease and cancer, smoking status, physical activity (if available), Healthy Diet Indicator score (if available), and BMI.

Figure 4. Forest plot with pooled Hazard Ratios (HRs) and 95\% Confidence Intervals (CIs) for the association between residuals of beer consumption per $6 \mathrm{~g} / \mathrm{d}$ and diabetes incidence adjusted for absolute alcohol intake, age, sex, education, employment status, prevalent coronary heart disease and cancer, smoking status, physical activity (if available), Healthy Diet Indicator score (if available), and BMI. 
Figure 5. Forest plot with pooled Hazard Ratios (HRs) and 95\% Confidence Intervals (CIs)

710 for the association between residuals of wine consumption per $6 \mathrm{~g} / \mathrm{d}$ and diabetes incidence

711 adjusted for absolute alcohol intake, age, sex, education, employment status, prevalent

712 coronary heart disease and cancer, smoking status, physical activity (if available), Healthy

713 Diet Indicator score (if available), and BMI.

714 Figure 6. Forest plot with pooled Hazard Ratios (HRs) and 95\% Confidence Intervals (CIs)

715 for the association between residuals of spirit consumption per $6 \mathrm{~g} / \mathrm{d}$ and diabetes incidence

716 adjusted for absolute alcohol intake, age, sex, education, employment status, prevalent

717 coronary heart disease and cancer, smoking status, physical activity (if available), Healthy

718 Diet Indicator score (if available), and BMI. 
Figure 1. Forest plot with pooled Hazard Ratios (HRs) and 95\% Confidence Intervals (CIs) for the association between beer preference and diabetes incidence compared to having no preference adjusted for age, sex, education, employment status, prevalent coronary heart disease and cancer, smoking status, physical activity (if available), Healthy Diet Indicator score (if available), and BMI.

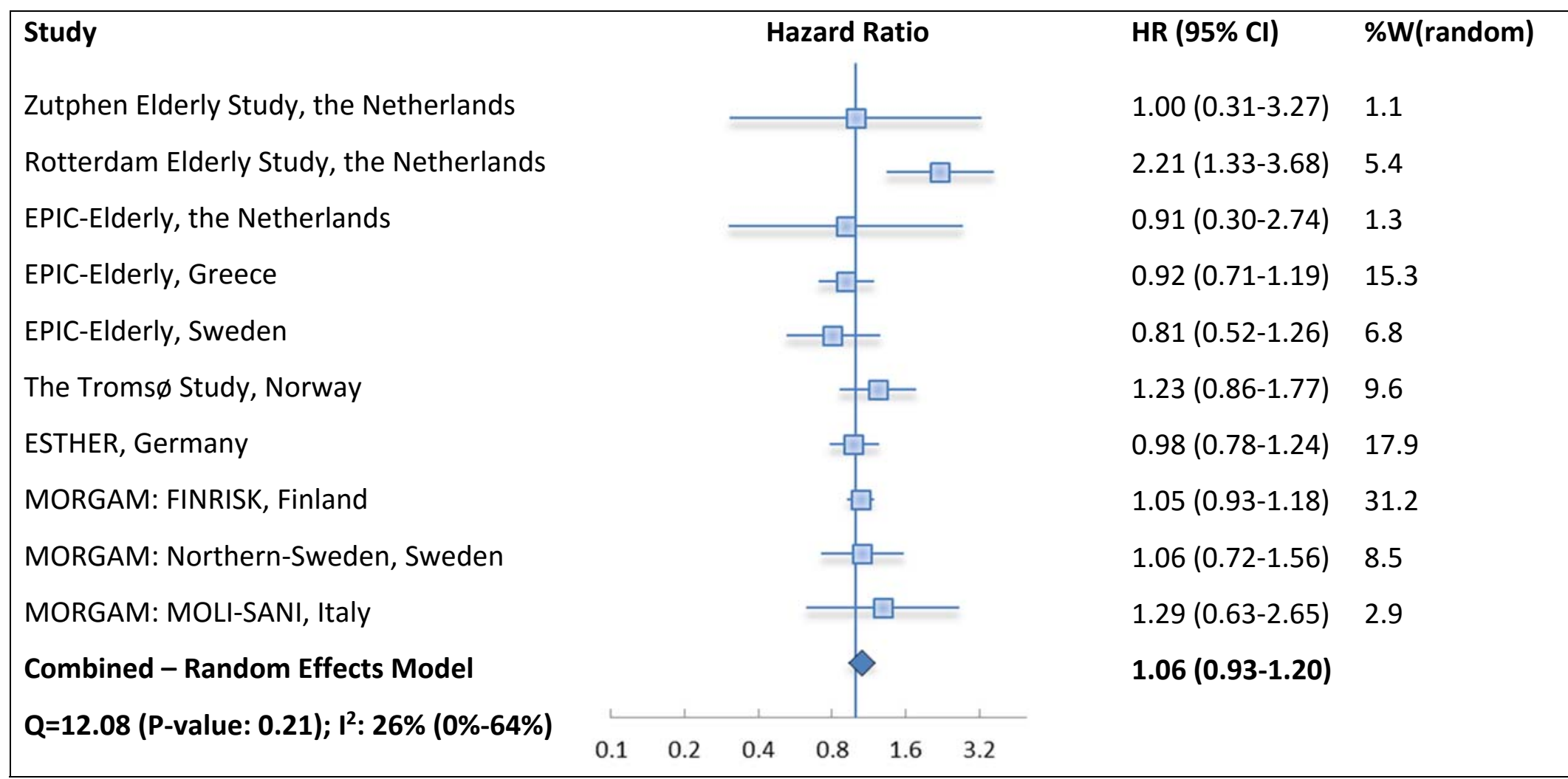


Figure 2. Forest plot with pooled Hazard Ratios (HRs) and 95\% Confidence Intervals (CIs) for the association between wine preference and diabetes incidence compared to having no preference adjusted for age, sex, education, employment status, prevalent coronary heart disease and cancer, smoking status, physical activity (if available), Healthy Diet Indicator score (if available), and BMI.

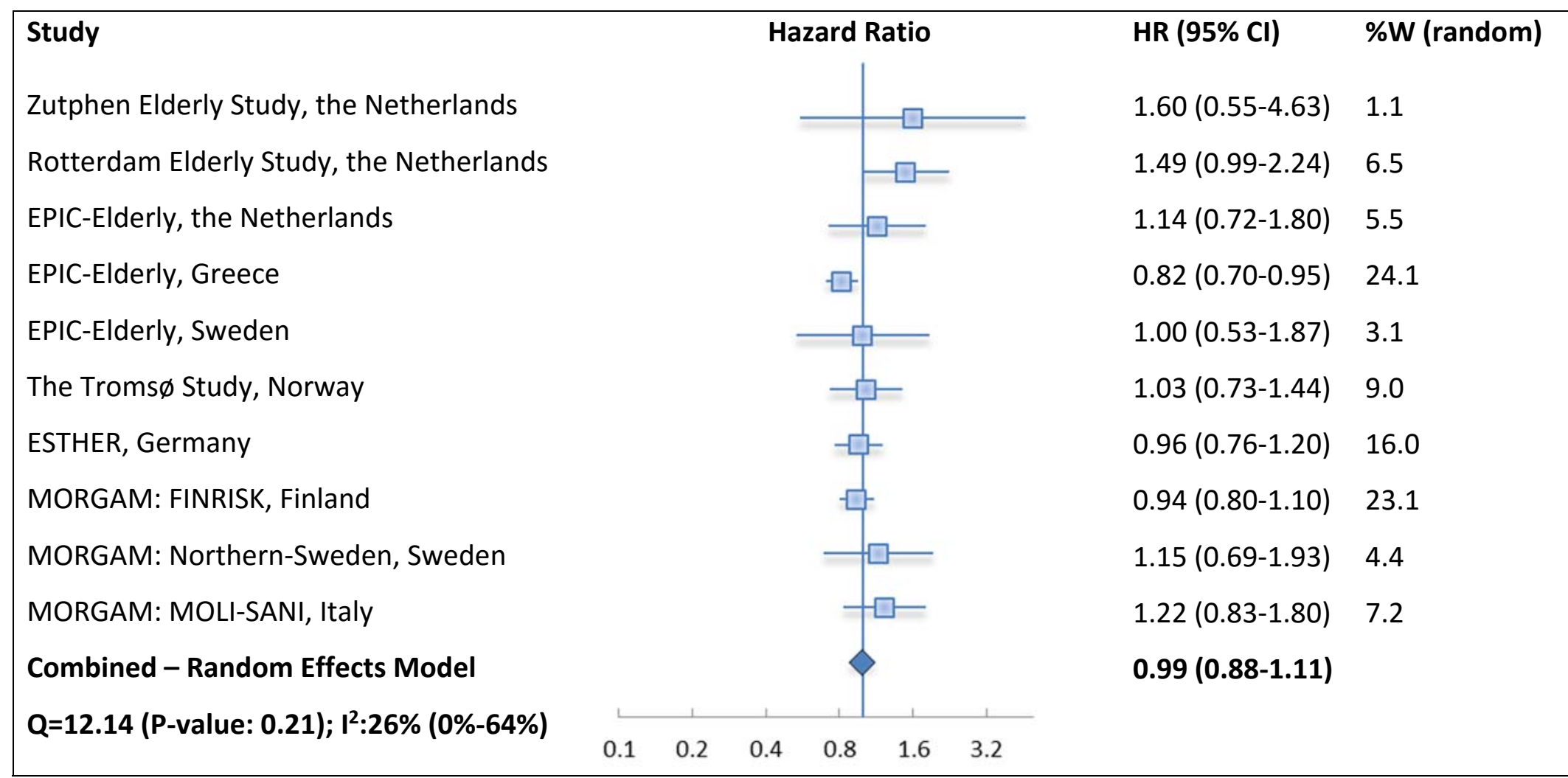


Figure 1. Forest plot with pooled Hazard Ratios (HRs) and 95\% Confidence Intervals (CIs) for the association between beer preference and diabetes incidence compared to having no preference adjusted for age, sex, education, employment status, prevalent coronary heart disease and cancer, smoking status, physical activity (if available), Healthy Diet Indicator score (if available), and BMI.

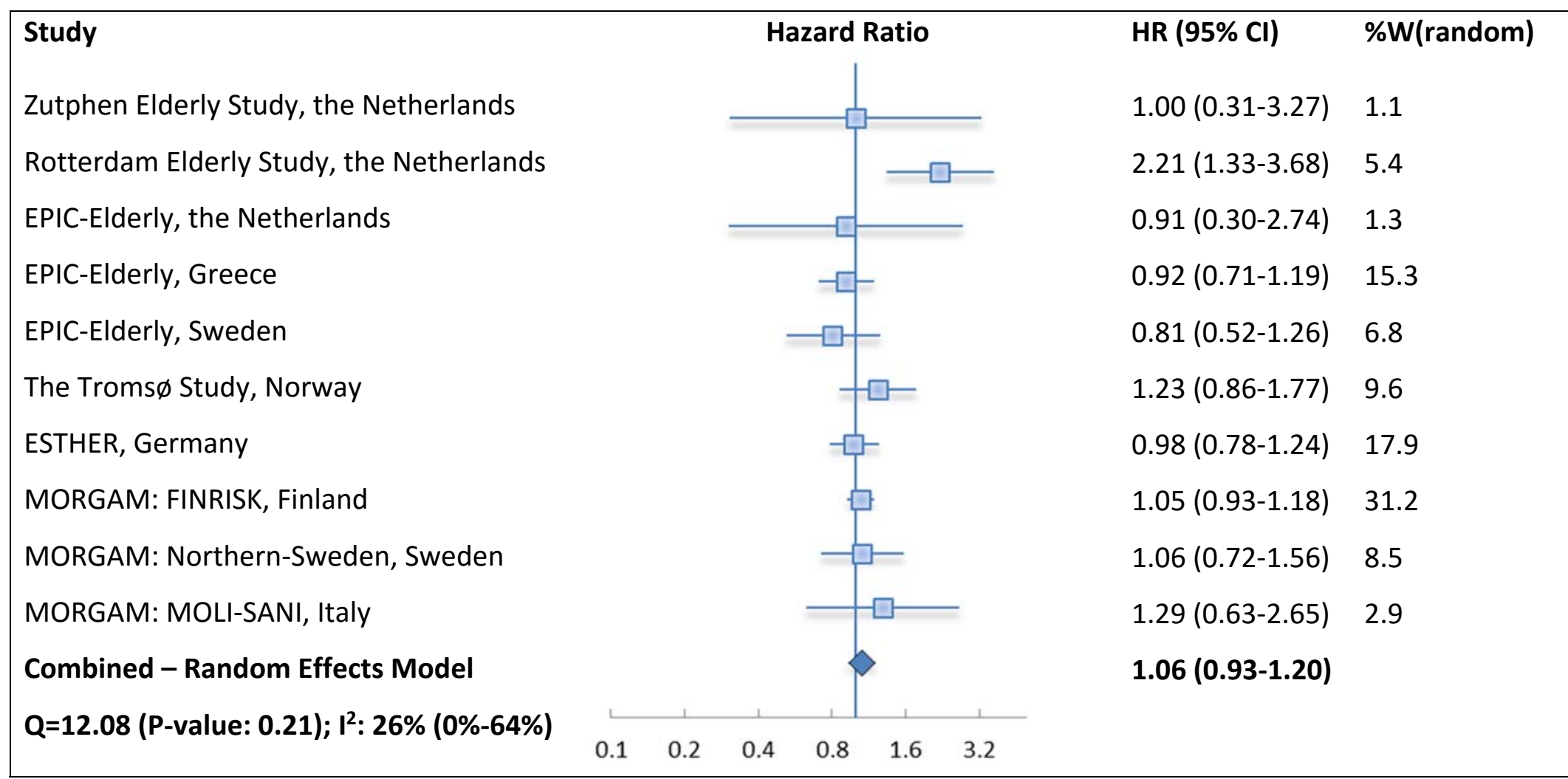


Figure 2. Forest plot with pooled Hazard Ratios (HRs) and 95\% Confidence Intervals (CIs) for the association between wine preference and diabetes incidence compared to having no preference adjusted for age, sex, education, employment status, prevalent coronary heart disease and cancer, smoking status, physical activity (if available), Healthy Diet Indicator score (if available), and BMI.

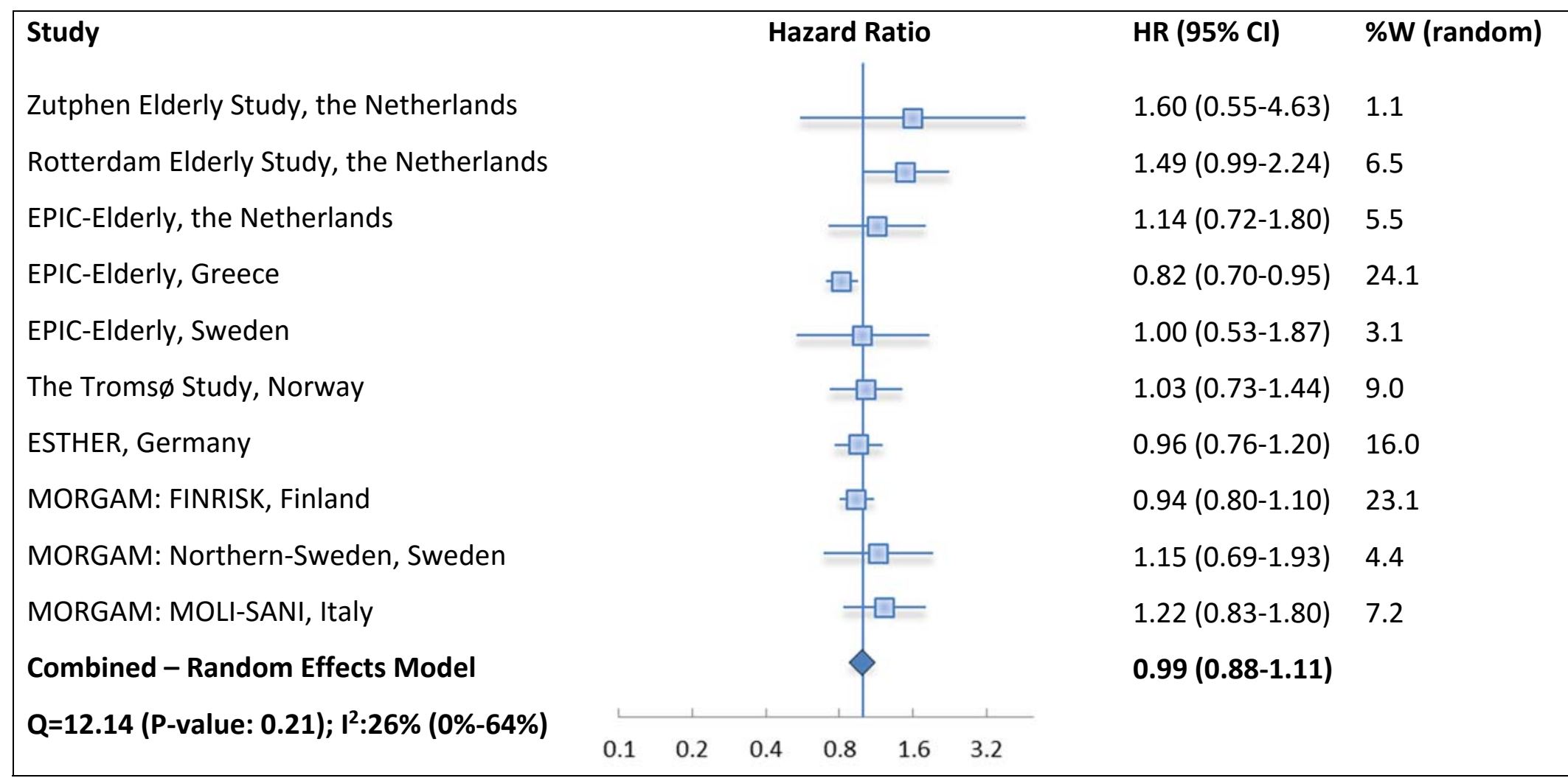


Figure 3. Forest plot with pooled Hazard Ratios (HRs) and 95\% Confidence Intervals (CIs) for the association between spirit preference and diabetes incidence compared to having no preference adjusted for age, sex, education, employment status, prevalent coronary heart disease and cancer, smoking status, physical activity (if available), Healthy Diet Indicator score (if available), and BMI.

\begin{tabular}{|c|c|c|c|c|c|}
\hline Study & & Hazar & d Ratio & $\mathrm{HR}(95 \% \mathrm{Cl})$ & \%W (random) \\
\hline Zutphen Elderly Study, the Netherlands & & & 6 & $1.60(0.55-4.63)$ & 3.9 \\
\hline Rotterdam Elderly Study, the Netherlands & & & $-\square-$ & $1.49(0.99-2.24)$ & 12.5 \\
\hline EPIC-Elderly, the Netherlands & & & 口- & $1.14(0.72-1.80)$ & 8.3 \\
\hline EPIC-Elderly, Greece & & & $-\square-$ & $0.82(0.70-0.95)$ & 17.0 \\
\hline EPIC-Elderly, Sweden & & $-\square$ & - & $1.00(0.53-1.87)$ & 5.8 \\
\hline The Troms $\varnothing$ Study, Norway & & & $\square$ & $1.03(0.73-1.44)$ & 15.4 \\
\hline ESTHER, Germany & & - & $+\square$ & $0.96(0.76-1.20)$ & 8.7 \\
\hline MORGAM: FINRISK, Finland & & & 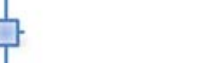 & $0.94(0.80-1.10)$ & 23.2 \\
\hline MORGAM: Northern-Sweden, Sweden & & $\square$ & + & $1.15(0.69-1.93)$ & 5.3 \\
\hline Combined - Random Effects Model & & & $\gamma$ & $1.19(0.97-1.46)$ & \\
\hline$Q=17.47$ (P-value: 0.03$) ; I^{2}: 54 \%$ (3\%-78\%) & $\begin{array}{ll} & 1 \\
0.1 & 0.2\end{array}$ & 0.4 & 1.6 & & \\
\hline
\end{tabular}


Figure 4. Forest plot with pooled Hazard Ratios (HRs) and 95\% Confidence Intervals (CIs) for the association between the residuals of beer consumption per $6 \mathrm{~g} / \mathrm{d}$ and diabetes incidence adjusted for absolute alcohol intake, age, sex, education, employment status, prevalent coronary heart disease and cancer, smoking status, physical activity (if available), Healthy Diet Indicator score (if available), and BMI.

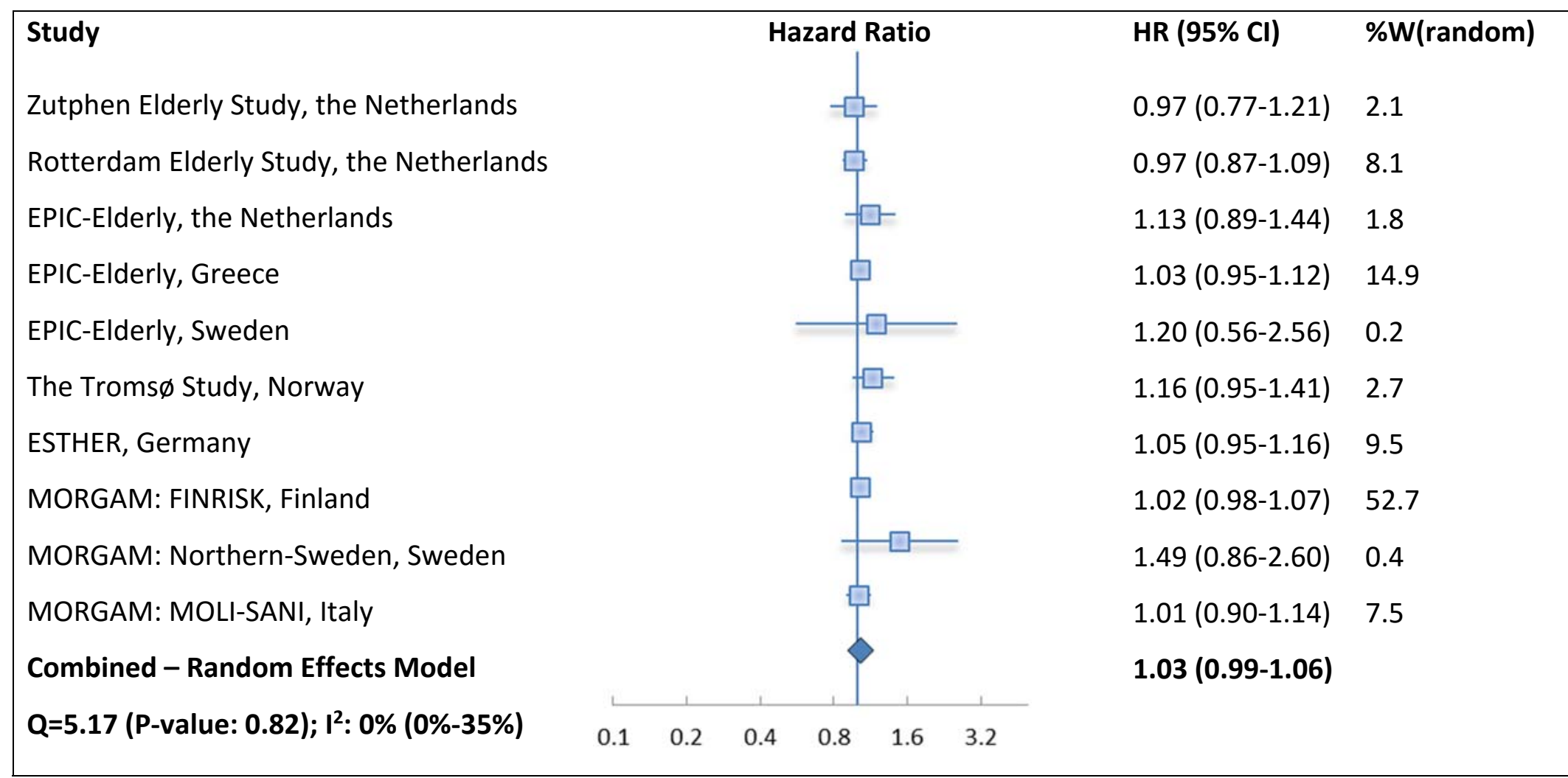


Figure 5. Forest plot with pooled Hazard Ratios (HRs) and 95\% Confidence Intervals (CIs) for the association between the residuals of wine consumption per $6 \mathrm{~g} / \mathrm{d}$ and diabetes incidence adjusted for absolute alcohol intake, age, sex, education, employment status, prevalent coronary heart disease and cancer, smoking status, physical activity (if available), Healthy Diet Indicator score (if available), and BMI.

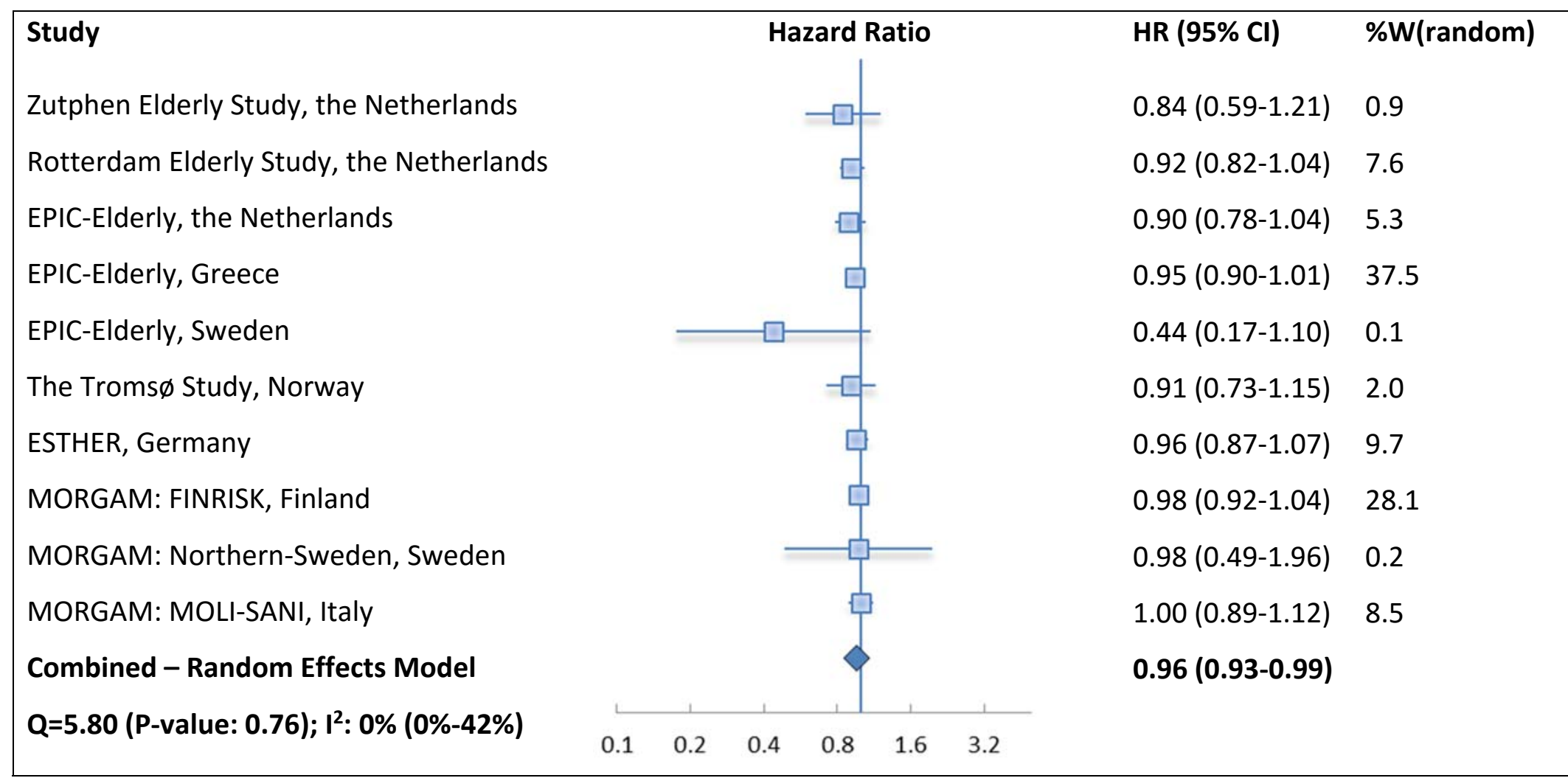


Figure 6. Forest plot with pooled Hazard Ratios (HRs) and 95\% Confidence Intervals (CIs) for the association between the residuals of spirit consumption per $6 \mathrm{~g} / \mathrm{d}$ and diabetes incidence adjusted for absolute alcohol intake, age, sex, education, employment status, prevalent coronary heart disease and cancer, smoking status, physical activity (if available), Healthy Diet Indicator score (if available), and BMI.

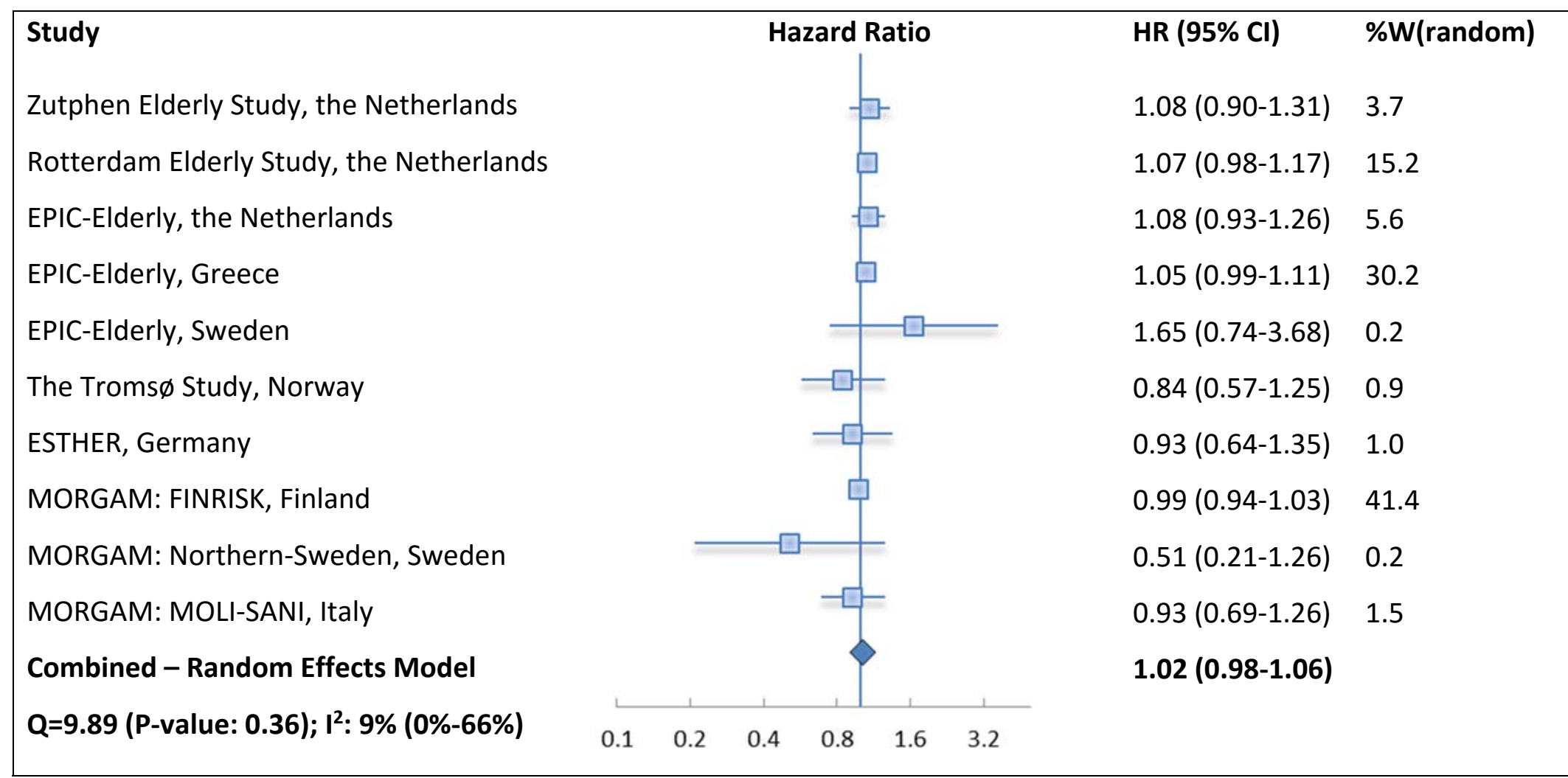


Supplemental Figure 1: Participant flow-charts of the ten included European cohort studies from the Consortium on Health and Ageing: Network of Cohorts in Europe and the United States (CHANCES) project.
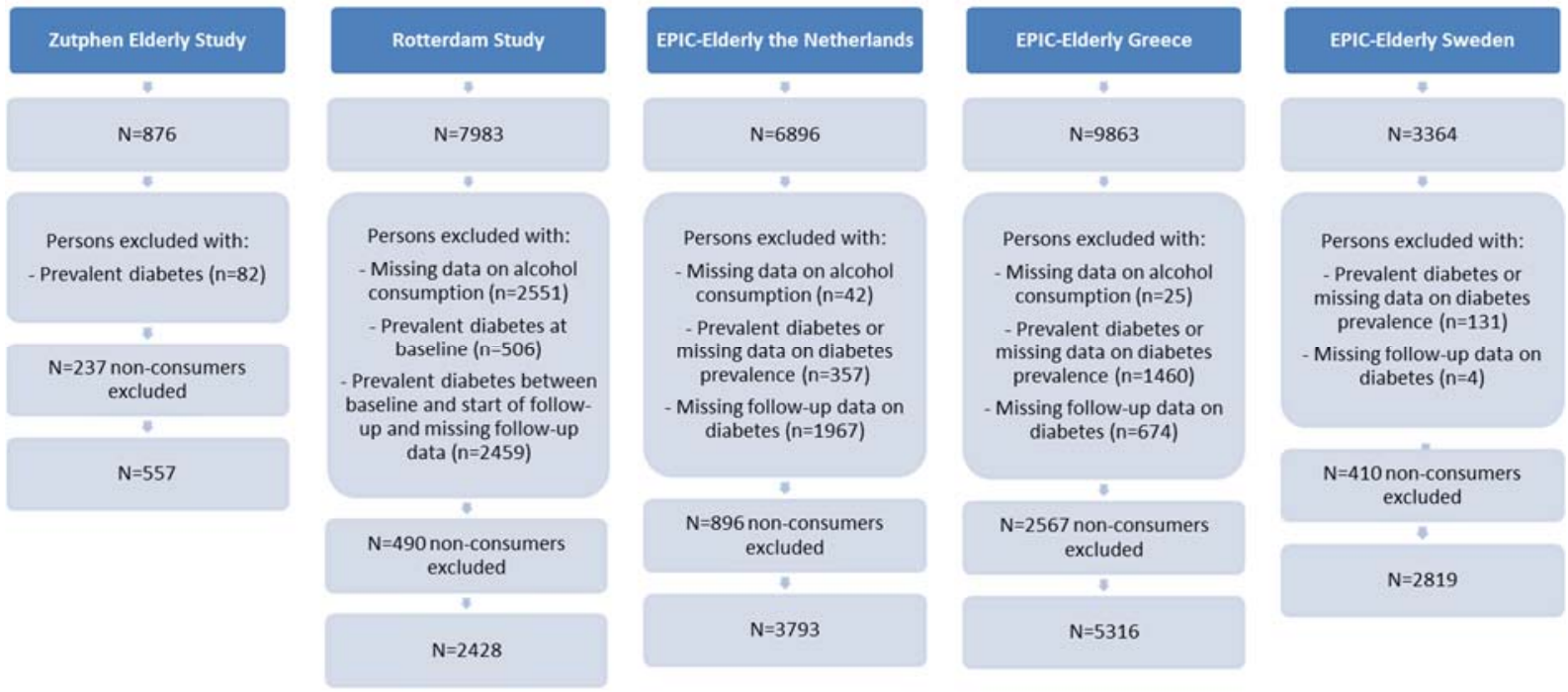

\section{Persons excluded with:}

- Prevalent diabetes or missing data on diabetes

prevalence $(n=131)$

- Missing follow-up data on diabetes $(n=4)$
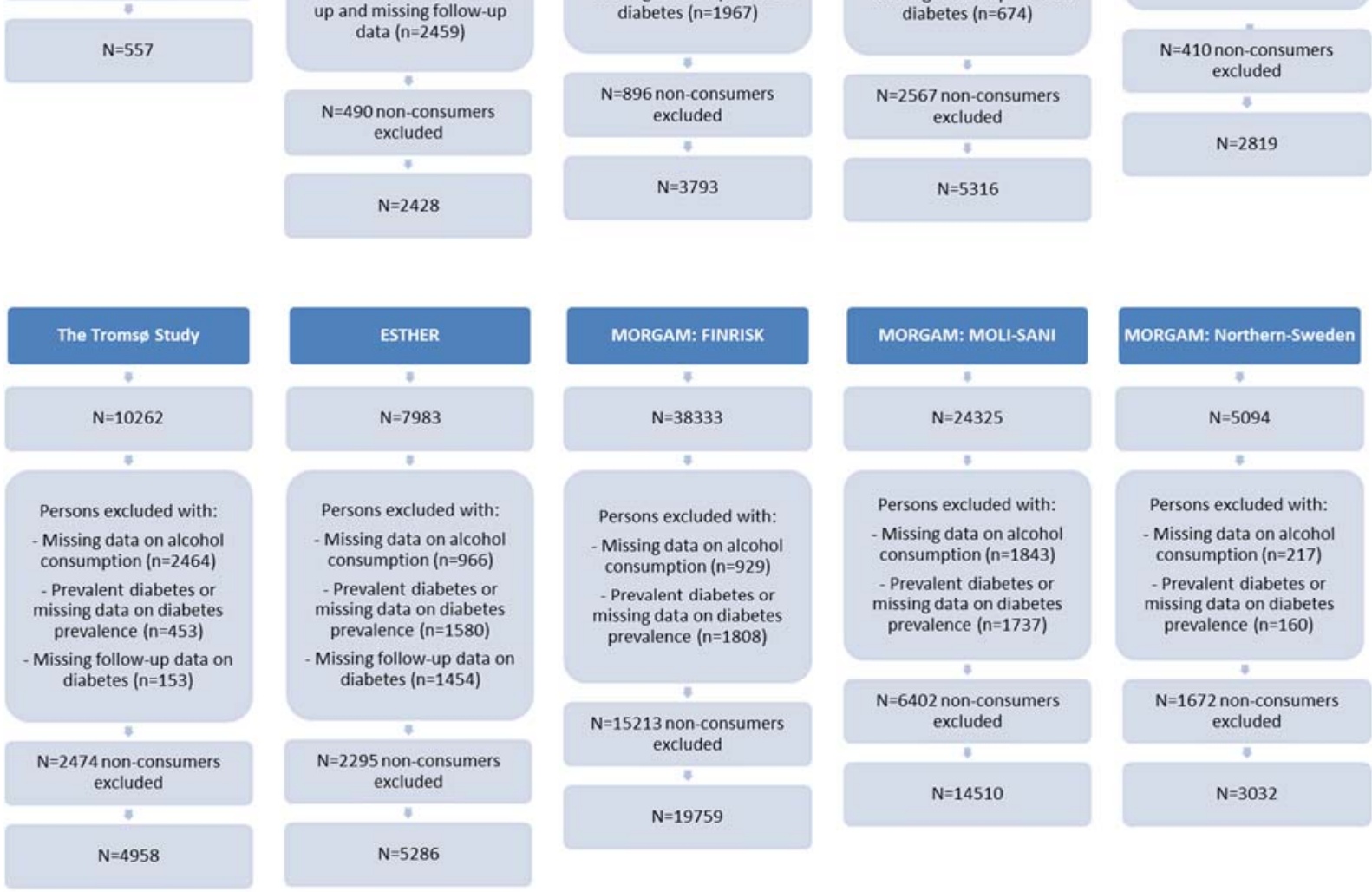

Persons excluded with:

Missing data on alcoho

consumption ( $n=1843$ )

- Prevalent diabetes or

missing data on diabetes prevalence ( $n=1737)$

Persons excluded with:

- Missing data on alcohol

consumption $(\mathrm{n}=217)$

- Prevalent diabetes or

missing data on diabetes prevalence ( $n=160$ )

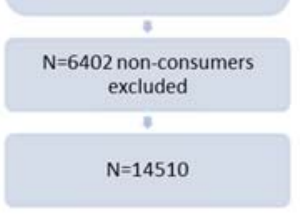
a

$\mathrm{N}=1672$ non-consumers excluded

$\mathrm{N}=3032$ 
Supplemental Table 1. Selected general characteristics across categories of alcoholic beverage preference and Hazard Ratios (HRs) and 95\% Confidence Intervals (CIs) of the associations between having a beer, wine, or spirit preference and diabetes incidence compared to having no preference in 10 European cohorts based on multiple imputation results.

\begin{tabular}{|c|c|c|c|c|}
\hline & Beer preference & Wine preference & Spirit preference & No preference \\
\hline \multicolumn{5}{|l|}{ Zutphen Elderly Study } \\
\hline $\mathrm{N}(\%)$ & $65(12)$ & $73(13)$ & $344(62)$ & $75(13)$ \\
\hline Age, years & $70.5(5.8)$ & $72.1(5.0)$ & $72.2(5.2)$ & $71.8(5.5)$ \\
\hline Men, $\%$ & 100 & 100 & 100 & 100 \\
\hline Ethanol consumption, g/day & $13.5[4.0-25.0]$ & $3.8[1.7-12.0]$ & $18.8[6.2-37.5$ & $20.3[8.4-44.9$ \\
\hline University or college education, $\%$ & 0 & 14 & 3 & 10 \\
\hline Current smokers, $\%$ & 32 & 23 & 41 & 29 \\
\hline \multicolumn{5}{|l|}{ BMI, $\mathrm{kg} / \mathrm{m}^{2}$} \\
\hline - Crude & $26.0(0.4)$ & $24.7(0.4)^{*}$ & $25.5(0.2)$ & $25.3(0.4)$ \\
\hline - Adjusted $^{\mathrm{a}}$ & $25.9(0.4)$ & $25.0(0.4)$ & $25.5(0.2)$ & $25.3(0.4)$ \\
\hline Diabetes cases / Person Years & $6 / 756$ & $9 / 747$ & $27 / 3529$ & $6 / 848$ \\
\hline HR (95\% CI): Model 1 & $1.00(0.32-3.18)$ & $1.34(0.46-3.89)$ & $0.95(0.39-2.32)$ & 1.00 (ref) \\
\hline HR (95\% CI): Model 2 & $1.04(0.32-4.15)$ & $1.46(0.52-4.15)$ & $0.96(0.38-2.42)$ & 1.00 (ref) \\
\hline HR (95\% CI): Model 3 & $1.00(0.31-3.27)$ & $1.60(0.55-4.63)$ & $1.07(0.42-2.77)$ & 1.00 (ref) \\
\hline \multicolumn{5}{|l|}{$\underline{\text { Rotterdam Study }}$} \\
\hline $\mathrm{N}(\%)$ & $182(7)$ & $1292(53)$ & $582(24)$ & $372(15)$ \\
\hline Age, years & $62.4(5.8)$ & $64.8(6.8)$ & $66.2(6.5)$ & $64.0(6.1)$ \\
\hline
\end{tabular}


Supplemental Table 1 (continued). Selected general characteristics across categories of alcoholic beverage preference and Hazard Ratios (HRs) and 95\% Confidence Intervals (CIs) of the associations between having a beer, wine, or spirit preference and diabetes incidence compared to having no preference in 10 European cohorts based on multiple imputation results.

\begin{tabular}{|c|c|c|c|c|}
\hline & Beer preference & Wine preference & Spirit preference & No preference \\
\hline Men, $\%$ & 88 & 17 & 72 & 71 \\
\hline Ethanol consumption, g/day & $11.7[3.0-25.7]$ & $2.9[0.6-9.1]$ & $18.9[7.5-31.8]$ & $11.3[3.6-24.9]$ \\
\hline University or college education, $\%$ & 13 & 8 & 11 & 18 \\
\hline Current smokers, $\%$ & 31 & 17 & 28 & 22 \\
\hline \multicolumn{5}{|l|}{ BMI, $\mathrm{kg} / \mathrm{m}^{2}$} \\
\hline - Crude & $25.4(0.3)$ & $26.1(0.1)^{*}$ & $26.2(0.1)^{*}$ & $25.7(0.2)^{* * * * * *}$ \\
\hline - Adjusted $^{\mathrm{a}}$ & $25.6(0.3)$ & $26.0(0.1)$ & $26.4(0.2)^{*, * *}$ & $26.0(0.2)^{* * *}$ \\
\hline Diabetes cases / Person Years & $30 / 1756$ & $155 / 13447$ & $100 / 5321$ & $32 / 3920$ \\
\hline HR (95\% CI): Model 1 & $2.10(1.27-3.47)$ & $1.43(0.96-2.15)$ & $2.30(1.54-3.43)$ & 1.00 (ref) \\
\hline HR (95\% CI): Model 2 & $2.15(1.29-3.57)$ & $1.48(0.98-2.24)$ & $2.38(1.58-3.57)$ & 1.00 (ref) \\
\hline HR (95\% CI): Model 3 & $2.21(1.33-3.68)$ & $1.49(0.99-2.24)$ & $2.28(1.52-3.43)$ & 1.00 (ref) \\
\hline \multicolumn{5}{|l|}{ EPIC-Elderly the Netherlands } \\
\hline $\mathrm{N}(\%)$ & $82(2)$ & $2802(74)$ & $384(10)$ & $525(14)$ \\
\hline Age, years & $63.7(2.6)$ & $64.2(2.7)$ & $64.1(2.5)$ & $64.2(2.7)$ \\
\hline Men, $\%$ & 39 & 2 & 13 & 12 \\
\hline Ethanol consumption, g/day & $7.3[1.3-20.1]$ & $4.4[1.3-13.1]$ & $10.1[1.8-25.7]$ & $4.9[1.5-12.8]$ \\
\hline University or college education, $\%$ & 7 & 16 & 8 & 12 \\
\hline Current smokers, $\%$ & 40 & 15 & 29 & 17 \\
\hline
\end{tabular}


Supplemental Table 1 (continued). Selected general characteristics across categories of alcoholic beverage preference and Hazard Ratios (HRs) and 95\% Confidence Intervals (CIs) of the associations between having a beer, wine, or spirit preference and diabetes incidence compared to having no preference in 10 European cohorts based on multiple imputation results.

\begin{tabular}{|c|c|c|c|c|}
\hline & Beer preference & Wine preference & Spirit preference & No preference \\
\hline \multicolumn{5}{|l|}{ BMI, $\mathrm{kg} / \mathrm{m}^{2}$} \\
\hline - Crude & $25.2(0.4)$ & $25.5(0.1)$ & $26.4(0.2) * * *$ & $25.6(0.2)^{* * *}$ \\
\hline - Adjusted $^{\mathrm{a}}$ & $25.0(0.4)$ & $25.7(0.1)$ & $26.3(0.2) * * *$ & $25.6(0.2)^{* * *}$ \\
\hline Diabetes cases / Person Years & $4 / 416$ & $167 / 13601$ & $26 / 1927$ & $22 / 2559$ \\
\hline HR (95\% CI): Model 1 & $0.75(0.25-2.22)$ & $1.28(0.81-2.02)$ & $1.22(0.69-2.17)$ & 1.00 (ref) \\
\hline HR (95\% CI): Model 2 & $0.88(0.29-2.57)$ & $1.23(0.78-1.94)$ & $1.20(0.67-2.13)$ & 1.00 (ref) \\
\hline HR (95\% CI): Model 3 & $0.91(0.30-2.74)$ & $1.14(0.72-1.80)$ & $1.11(0.63-1.98)$ & 1.00 (ref) \\
\hline \multicolumn{5}{|l|}{ EPIC-EIderly Greece } \\
\hline $\mathrm{N}(\%)$ & $510(10)$ & $2561(48)$ & $361(7)$ & $1884(35)$ \\
\hline Age, years & $66.2(4.5)$ & $67.4(4.5)$ & $67.0(4.3)$ & $66.3(4.3)$ \\
\hline Men, $\%$ & 47 & 46 & 74 & 52 \\
\hline Ethanol consumption, g/day & $1.3[0.6-8.5]$ & $8.0[1.2-16.0]$ & $13.2[4.4-21.3]$ & $2.8[1.3-12.5]$ \\
\hline University or college education, $\%$ & 4 & 2 & 3 & 7 \\
\hline Current smokers, $\%$ & 12 & 13 & 29 & 16 \\
\hline \multicolumn{5}{|l|}{ BMI, $\mathrm{kg} / \mathrm{m}^{2}$} \\
\hline - Crude & $29.2(0.2)$ & $28.9(0.1)$ & $28.9(0.2)$ & $28.8(0.1)$ \\
\hline - Adjusted $^{\mathrm{a}}$ & $29.0(0.2)$ & $28.7(0.1)$ & $29.4(0.2)^{* *}$ & $29.0(0.1)$ \\
\hline Diabetes cases / Person Years & $72 / 5407$ & $377 / 28107$ & $58 / 3717$ & $308 / 20618$ \\
\hline HR (95\% CI): Model 1 & $0.99(0.77-1.28)$ & $0.78(0.67-0.91)$ & $1.37(1.03-1.82)$ & 1.00 (ref) \\
\hline
\end{tabular}


Supplemental Table 1 (continued). Selected general characteristics across categories of alcoholic beverage preference and Hazard Ratios (HRs) and 95\% Confidence Intervals (CIs) of the associations between having a beer, wine, or spirit preference and diabetes incidence compared to having no preference in 10 European cohorts based on multiple imputation results.

\begin{tabular}{|c|c|c|c|c|}
\hline & Beer preference & Wine preference & Spirit preference & No preference \\
\hline HR (95\% CI): Model 2 & $0.98(0.76-1.27)$ & $0.80(0.69-0.94)$ & $1.32(1.00-1.76)$ & 1.00 (ref) \\
\hline HR (95\% CI): Model 3 & $0.92(0.71-1.19)$ & $0.82(0.70-0.95)$ & $1.27(0.95-1.68)$ & 1.00 (ref) \\
\hline \multicolumn{5}{|l|}{ EPIC-EIderly Sweden } \\
\hline $\mathrm{N}(\%)$ & $958(34)$ & $413(15)$ & $137(5)$ & $1311(47)$ \\
\hline Age, years & $60.4(1.3)$ & $60.3(0.9)$ & $60.4(1.2)$ & $60.3(0.8)$ \\
\hline Men, $\%$ & 58 & 15 & 77 & 54 \\
\hline Ethanol consumption, g/day & $0.9[0.3-2.7]$ & $1.6[0.1-3.3]$ & $2.0[0.2-2.4]$ & $2.9[0.4-5.4]$ \\
\hline University or college education, $\%$ & 11 & 18 & 5 & 13 \\
\hline Current smokers, $\%$ & 13 & 13 & 40 & 22 \\
\hline \multicolumn{5}{|l|}{ BMI, $\mathrm{kg} / \mathrm{m}^{2}$} \\
\hline - Crude & $25.6(0.1)$ & $25.5(0.2)$ & $26.7(0.3) * * *$ & $25.9(0.1)^{* * *}$ \\
\hline - Adjusted $^{\mathrm{a}}$ & $25.5(0.1)$ & $25.5(0.2)$ & $26.8(0.3) * * *$ & $26.0(0.1)^{*}, * * *$ \\
\hline Diabetes cases / Person Years & $33 / 12680$ & $14 / 5406$ & $9 / 1821$ & $53 / 17276$ \\
\hline HR (95\% CI): Model 1 & $0.81(0.52-1.25)$ & $1.00(0.54-1.86)$ & $1.34(0.65-2.74)$ & 1.00 (ref) \\
\hline HR (95\% CI): Model 2 & $0.80(0.52-1.25)$ & $1.00(0.53-1.86)$ & $1.31(0.63-2.81)$ & 1.00 (ref) \\
\hline HR (95\% CI): Model 3 & $0.81(0.52-1.26)$ & $1.00(0.53-1.87)$ & $0.92(0.44-1.93)$ & 1.00 (ref) \\
\hline \multicolumn{5}{|l|}{ The Tromso Study } \\
\hline $\mathrm{N}(\%)$ & $722(15)$ & $1502(30)$ & $1042(21)$ & $1692(34)$ \\
\hline
\end{tabular}


Supplemental Table 1 (continued). Selected general characteristics across categories of alcoholic beverage preference and Hazard Ratios (HRs) and 95\% Confidence Intervals (CIs) of the associations between having a beer, wine, or spirit preference and diabetes incidence compared to having no preference in 10 European cohorts based on multiple imputation results.

\begin{tabular}{|c|c|c|c|c|}
\hline & Beer preference & Wine preference & Spirit preference & No preference \\
\hline Age, years & $59.6(8.4)$ & $59.8(8.8)$ & $62.1(8.6)$ & $58.7(7.7)$ \\
\hline Men, $\%$ & 76 & 28 & 74 & 71 \\
\hline Ethanol consumption, g/day & $3.3[1.7-6.1]$ & $4.7[2.4-7.1]$ & $1.1[1.1-2.6]$ & $4.7[2.8-8.1]$ \\
\hline University or college education, $\%$ & 18 & 33 & 10 & 28 \\
\hline Current smokers, $\%$ & 38 & 29 & 50 & 34 \\
\hline \multicolumn{5}{|l|}{ BMI, kg/m² } \\
\hline - Crude & $25.4(0.1)$ & $25.4(0.1)$ & $25.9(0.1) * * *$ & $25.9(0.1) * * *$ \\
\hline - Adjusted ${ }^{\mathrm{a}}$ & $25.3(0.1)$ & $25.6(0.1)$ & $25.9(0.1) * * *$ & $25.8(0.1)^{* *}$ \\
\hline Diabetes cases / Person Years & $45 / 9158$ & $65 / 19853$ & $72 / 12715$ & $96 / 22094$ \\
\hline HR (95\% CI): Model 1 & $1.12(0.78-1.60)$ & $0.95(0.68-1.34)$ & $1.32(0.96-1.81)$ & 1.00 (ref) \\
\hline HR (95\% CI): Model 2 & $1.12(0.78-1.60)$ & $0.96(0.68-1.34)$ & $1.32(0.96-1.81)$ & 1.00 (ref) \\
\hline HR (95\% CI): Model 3 & $1.23(0.86-1.77)$ & $1.03(0.73-1.44)$ & $1.17(0.85-1.61)$ & 1.00 (ref) \\
\hline \multicolumn{5}{|l|}{ ESTHER } \\
\hline $\mathrm{N}(\%)$ & $1466(28)$ & $2305(44)$ & $107(2)$ & $1408(27)$ \\
\hline Age, years & $61.5(6.4)$ & $61.5(6.6)$ & $63.2(6.8)$ & $62.0(6.6)$ \\
\hline Men, $\%$ & 77 & 32 & 22 & 64 \\
\hline Ethanol consumption, g/day & $6.6[2.6-13.2]$ & $5.6[3.7-11.0]$ & $0.8[0.8-2.5]$ & $9.1[5.3-15.8]$ \\
\hline Middle education, $\%$ & 21 & 35 & 25 & 34 \\
\hline Current smokers, $\%$ & 26 & 13 & 13 & 14 \\
\hline
\end{tabular}


Supplemental Table 1 (continued). Selected general characteristics across categories of alcoholic beverage preference and Hazard Ratios (HRs) and 95\% Confidence Intervals (CIs) of the associations between having a beer, wine, or spirit preference and diabetes incidence compared to having no preference in 10 European cohorts based on multiple imputation results.

\begin{tabular}{|c|c|c|c|c|}
\hline & Beer preference & Wine preference & Spirit preference & No preference \\
\hline \multicolumn{5}{|l|}{ BMI, $\mathrm{kg} / \mathrm{m}^{2}$} \\
\hline - Crude & $27.6(0.1)$ & $26.8(0.1)^{*}$ & $28.0(0.4)^{* *}$ & $27.1(0.1) * * *, * * *$ \\
\hline - Adjusted $^{\mathrm{a}}$ & $27.4(0.1)$ & $27.0(0.1)^{*}$ & $28.2(0.4) * * *$ & $27.1(0.1)^{*}, * * *$ \\
\hline Diabetes cases / Person Years & $165 / 9671$ & $207 / 16394$ & $14 / 736$ & $140 / 9792$ \\
\hline HR (95\% CI): Model 1 & $1.07(0.85-1.35)$ & $0.98(0.79-1.23)$ & $1.42(0.81-2.47)$ & 1.00 (ref) \\
\hline HR (95\% CI): Model 2 & $1.05(0.83-1.32)$ & $0.97(0.78-1.22)$ & $1.39(0.80-2.43)$ & 1.00 (ref) \\
\hline HR (95\% CI): Model 3 & $0.98(0.78-1.24)$ & $0.96(0.76-1.20)$ & $1.25(0.71-2.18)$ & 1.00 (ref) \\
\hline \multicolumn{5}{|l|}{ MORGAM: FINRISK } \\
\hline $\mathrm{N}(\%)$ & $6410(32)$ & $3200(16)$ & $3410(17)$ & $6739(34)$ \\
\hline Age, years & $41.5(11.5)$ & $47.3(12.3)$ & $46.8(11.8)$ & $44.6(11.7)$ \\
\hline Men, $\%$ & 63 & 26 & 66 & 62 \\
\hline Ethanol consumption, g/day & $7.0[4.0-15.0]$ & $3.0[2.0-9.0]$ & $8.0[3.0-14.0]$ & $13.0[7.0-21.0]$ \\
\hline University or college education, $\%$ & 9 & 19 & 6 & 15 \\
\hline Current smokers, $\%$ & 38 & 17 & 34 & 29 \\
\hline \multicolumn{5}{|l|}{ BMI, $\mathrm{kg} / \mathrm{m}^{2}$} \\
\hline - Crude & $25.7(0.1)$ & $25.9(0.1)^{*}$ & $25.9(0.1) * * *$ & $26.2(0.1) * * * * * *$ \\
\hline - Adjusted $^{\text {aw }}$ & $25.9(0.1)$ & $26.1(0.1)$ & $25.5(0.1) * * *$ & $26.2(0.1)^{*}, * * *$ \\
\hline Diabetes cases / Person Years & $487 / 101570$ & $229 / 50342$ & $437 / 59893$ & $557 / 105820$ \\
\hline HR (95\% CI): Model 1 & $0.98(0.87-1.11)$ & $0.89(0.76-1.05)$ & $1.08(0.95-1.22)$ & 1.00 (ref) \\
\hline
\end{tabular}


Supplemental Table 1 (continued). Selected general characteristics across categories of alcoholic beverage preference and Hazard Ratios (HRs) and 95\% Confidence Intervals (CIs) of the associations between having a beer, wine, or spirit preference and diabetes incidence compared to having no preference in 10 European cohorts based on multiple imputation results.

\begin{tabular}{|c|c|c|c|c|}
\hline & Beer preference & Wine preference & Spirit preference & No preference \\
\hline HR (95\% CI): Model 2 & $0.97(0.86-1.10)$ & $0.91(0.78-1.07)$ & $1.07(0.94-1.21)$ & 1.00 (ref) \\
\hline HR (95\% CI): Model 3 & $1.05(0.93-1.18)$ & $0.94(0.80-1.10)$ & $1.00(0.88-1.13)$ & 1.00 (ref) \\
\hline \multicolumn{5}{|l|}{ MORGAM: Northern-Sweden } \\
\hline $\mathrm{N}(\%)$ & $794(26)$ & $511(17)$ & $146(5)$ & $1581(52)$ \\
\hline Age, years & $45.5(13.4)$ & $46.6(11.6)$ & $49.7(11.6)$ & $44.3(11.7)$ \\
\hline Men, $\%$ & 72 & 10 & 81 & 65 \\
\hline Ethanol consumption, g/day & $2.0[1.0-6.0]$ & $2.0[1.0-2.0]$ & $2.0[1.0-2.0]$ & $4.0[3.0-6.0]$ \\
\hline University or college education, $\%$ & 15 & 26 & 2 & 19 \\
\hline Current smokers, $\%$ & 23 & 27 & 40 & 30 \\
\hline \multicolumn{5}{|l|}{ BMI, $\mathrm{kg} / \mathrm{m}^{2}$} \\
\hline - Crude & $25.4(0.1)$ & $24.8(0.2)^{*}$ & $26.7(0.3) *, * *, * * *$ & $25.2(0.1) * *, * * *$ \\
\hline - Adjusted $^{\mathrm{a}}$ & $25.2(0.2)$ & $25.2(0.2)$ & $26.1(0.3) * * *$ & $25.2(0.1)^{* * *}$ \\
\hline Diabetes cases / Person Years & $40 / 15215$ & $25 / 10413$ & $7 / 2728$ & $77 / 31392$ \\
\hline HR (95\% CI): Model 1 & $0.99(0.67-1.46)$ & $1.05(0.63-1.73)$ & $0.88(0.40-1.93)$ & 1.00 (ref) \\
\hline HR (95\% CI): Model 2 & $1.04(0.71-1.54)$ & $1.10(0.66-1.83)$ & $0.87(0.40-1.90)$ & 1.00 (ref) \\
\hline HR (95\% CI): Model 3 & $1.06(0.72-1.56)$ & $1.15(0.69-1.93)$ & $0.68(0.31-1.50)$ & 1.00 (ref) \\
\hline \multicolumn{5}{|l|}{ MORGAM: MOLI-SANI } \\
\hline $\mathrm{N}(\%)$ & $618(4)$ & $11522(79)$ & $102(1)$ & $2268(16)$ \\
\hline
\end{tabular}


Supplemental Table 1 (continued). Selected general characteristics across categories of alcoholic beverage preference and Hazard Ratios (HRs) and 95\% Confidence Intervals (CIs) of the associations between having a beer, wine, or spirit preference and diabetes incidence compared to having no preference in 10 European cohorts based on multiple imputation results.

\begin{tabular}{|lllll|}
\hline & Beer preference & Wine preference & Spirit preference & No preference \\
\hline Age, years & $49.6(9.9)$ & $56.7(11.7)$ & $50.7(9.3)$ & $49.6(9.7)$ \\
\hline Men, \% & 62 & 60 & 34 & 64 \\
\hline Ethanol consumption, g/day & $4.0[1.0-17.0]$ & $18.0[10.0-34.0]$ & $2.0[2.0-7.0]$ & $8.0[3.0-20.0]$ \\
\hline University or college education, $\%$ & 13 & 12 & 14 & 17 \\
\hline Current smokers, \% & 35 & 22 & 25 & 27 \\
\hline BMI, kg/m ${ }^{2}$ & & & $26.9(0.4)^{* *}$ & $27.6(0.1)^{* *}$ \\
\hline - Crude & $27.3(0.2)$ & $27.8(0.0)^{*}$ & $27.5(0.4)$ & $28.0(0.1)^{* *}$ \\
\hline - Adjusted & $27.7(0.2)$ & $27.7(0.0)$ & $0 / 478$ & $30 / 10319$ \\
\hline Diabetes cases / Person Years & $10 / 2758$ & $255 / 20198$ & $1.00($ ref $)$ \\
\hline HR $(95 \%$ CI): Model 1 & $1.21(0.59-2.49)$ & $1.17(0.80-1.73)$ & no cases & $1.00($ ref $)$ \\
\hline HR $(95 \%$ CI): Model 2 & $1.19(0.58-2.44)$ & $1.17(0.80-1.73)$ & no cases & $1.00($ ref $)$ \\
\hline HR $(95 \%$ CI): Model 3 & $1.29(0.63-2.65)$ & $1.22(0.89-1.80)$ & no cases & \\
\hline
\end{tabular}

* P-value $<0.05$ versus beer preference; $* * \mathrm{P}$-value $<0.05$ versus wine preference; $* * * \mathrm{P}$-value $<0.05$ versus spirit preference.

${ }^{a}$ BMI adjusted for age, sex, education, employment, prevalent coronary heart disease or cancer, smoking status, sports activity (if available), and Healthy Diet Indicator (if available).

Model 1: Adjusted for age, sex, education, employment, and prevalent coronary heart disease or cancer;

Model 2: Model 1 additionally adjusted for smoking status, sports activity (if available), and Healthy Diet Indicator score (if available).

Model 3: Model 2 additionally adjusted for BMI. 
Supplemental Table 2. Hazard Ratios (HRs) and 95\% Confidence Intervals (CIs) of the associations between residuals of absolute consumption of beer, wine, and spirits and diabetes incidence in 10 European cohorts.

\begin{tabular}{|c|c|c|c|c|}
\hline Zutphen Elderly Study & Q1 & $\mathbf{Q 2}$ & Q3 & Per 6 g/d \\
\hline \multicolumn{5}{|c|}{ Beer consumption (residuals) } \\
\hline $\mathrm{N}$ & 185 & 186 & 186 & 557 \\
\hline Cases / Person Years & $14 / 1968$ & $18 / 1903$ & $16 / 2009$ & $48 / 5880$ \\
\hline HR (95\% CI): Model 1 & 1.00 (ref) & $1.47(0.71-3.02)$ & $1.25(0.60-2.64)$ & $0.98(0.80-1.20)$ \\
\hline HR (95\% CI): Model 2 & 1.00 (ref) & $1.47(0.71-3.05)$ & $1.30(0.61-2.77)$ & $0.98(0.79-1.21)$ \\
\hline HR (95\% CI): Model 3 & 1.00 (ref) & $1.47(0.70-3.07)$ & $1.23(0.58-2.62)$ & $0.97(0.77-1.21)$ \\
\hline \multicolumn{5}{|c|}{ Wine consumption (residuals) } \\
\hline $\mathrm{N}$ & 190 & 181 & 186 & 557 \\
\hline Cases / Person Years & $15 / 1915$ & $14 / 1859$ & $19 / 2106$ & $48 / 5880$ \\
\hline HR (95\% CI): Model 1 & 1.00 (ref) & $0.92(0.44-1.91)$ & $1.25(0.62-2.52)$ & $0.89(0.64-1.23)$ \\
\hline HR (95\% CI): Model 2 & 1.00 (ref) & $0.93(0.45-1.95)$ & $1.19(0.58-2.43)$ & $0.85(0.60-1.20)$ \\
\hline HR (95\% CI): Model 3 & 1.00 (ref) & $0.90(0.43-1.90)$ & $1.12(0.55-2.30)$ & $0.84(0.59-1.21)$ \\
\hline \multicolumn{5}{|c|}{ Spirit consumption (residuals) } \\
\hline $\mathrm{N}$ & 189 & 184 & 184 & 557 \\
\hline Cases / Person Years & $20 / 2095$ & $13 / 1952$ & $15 / 1833$ & $48 / 5880$ \\
\hline HR (95\% CI): Model 1 & 1.00 (ref) & $0.69(0.34-1.41)$ & $0.77(0.39-1.54)$ & $1.06(0.88-1.26)$ \\
\hline HR (95\% CI): Model 2 & 1.00 (ref) & $0.73(0.35-1.50)$ & $0.81(0.41-1.63)$ & $1.07(0.89-1.28)$ \\
\hline HR (95\% CI): Model 3 & 1.00 (ref) & $0.81(0.39-1.68)$ & $0.94(0.47-1.90)$ & $1.08(0.09-1.31)$ \\
\hline
\end{tabular}


Supplemental Table 2 (continued). Hazard Ratios (HRs) and 95\% Confidence Intervals (CIs) of the associations between residuals of absolute consumption of beer, wine, and spirits and diabetes incidence in 10 European cohorts.

\begin{tabular}{|lllll|}
\hline Rotterdam Study & Q1 & Q2 & Q3 & Per 6 g/d \\
\hline Beer consumption (residuals) & & & & \\
\hline N $(\%)$ & 809 & 815 & 804 & 2428 \\
\hline Cases / Person Years & $109 / 8118$ & $112 / 8283$ & $96 / 8042$ & $317 / 24444$ \\
\hline HR $(95 \%$ CI): Model 1 & $1.00(\mathrm{ref})$ & $1.07(0.82-1.41)$ & $0.88(0.67-1.17)$ & $0.98(0.87-1.10)$ \\
\hline HR $(95 \%$ CI): Model 2 & $1.00(\mathrm{ref})$ & $1.08(0.82-1.42)$ & $0.88(0.66-1.17)$ & $0.97(0.86-1.10)$ \\
\hline HR $(95 \%$ CI): Model 3 & $1.00(\mathrm{ref})$ & $1.06(0.80-1.39)$ & $0.87(0.62-1.15)$ & $0.97(0.87-1.09)$ \\
\hline Wine consumption (residuals) & & & & \\
\hline N $(\%)$ & 810 & 819 & 799 & 2428 \\
\hline Cases / Person Years & $125 / 7627$ & $99 / 8250$ & $93 / 8567$ & $317 / 24444$ \\
\hline HR $(95 \%$ CI): Model 1 & $1.00(\mathrm{ref})$ & $0.74(0.55-1.00)$ & $0.67(0.50-0.90)$ & $0.89(0.79-1.01)$ \\
\hline HR $(95 \%$ CI): Model 2 & $1.00(\mathrm{ref})$ & $0.74(0.55-1.00)$ & $0.68(0.50-0.91)$ & $0.90(0.79-1.01)$ \\
\hline HR $(95 \%$ CI): Model 3 & $1.00(\mathrm{ref})$ & $0.79(0.54-0.98)$ & $0.72(0.54-0.98)$ & $0.92(0.82-1.04)$ \\
\hline Spirit consumption (residuals) & & & & \\
\hline N $(\%)$ & 810 & 819 & 799 & 2428 \\
\hline Cases / Person Years & $89 / 8471$ & $110 / 8359$ & $118 / 7613$ & $317 / 24444$ \\
\hline HR $(95 \%$ CI): Model 1 & $1.00(\mathrm{ref})$ & $1.28(0.96-1.70)$ & $1.43(1.08-1.91)$ & $1.09(0.99-1.19)$ \\
\hline HR (95\% CI): Model 2 & $1.00(\mathrm{ref})$ & $1.30(0.97-1.72)$ & $1.41(1.06-1.87)$ & $1.09(0.99-1.19)$ \\
\hline HR (95\% CI): Model 3 & $1.00(\mathrm{ref})$ & $1.26(0.95-1.68)$ & $1.33(1.00-1.77)$ & $1.07(0.98-1.17)$ \\
\hline
\end{tabular}


Supplemental Table 2 (continued). Hazard Ratios (HRs) and 95\% Confidence Intervals (CIs) of the associations between residuals of absolute consumption of beer, wine, and spirits and diabetes incidence in 10 European cohorts.

\begin{tabular}{|c|c|c|c|c|}
\hline EPIC-ELDERLY: The Netherlands & Q1 & Q2 & Q3 & Per $6 \mathrm{~g} / \mathrm{d}$ \\
\hline \multicolumn{5}{|l|}{ Beer consumption (residuals) } \\
\hline $\mathrm{N}$ & 1264 & 1265 & 1264 & 3793 \\
\hline Cases / Person Years & $67 / 6097$ & $71 / 6120$ & $81 / 6286$ & $219 / 18503$ \\
\hline HR (95\% CI): Model 1 & 1.00 (ref) & $1.01(0.72-1.41)$ & $0.97(0.69-1.35)$ & $1.07(0.85-1.36)$ \\
\hline HR (95\% CI): Model 2 & 1.00 (ref) & $0.95(0.67-1.35)$ & $0.96(0.68-1.35)$ & $1.10(0.87-1.40)$ \\
\hline HR (95\% CI): Model 3 & 1.00 (ref) & $0.79(0.55-1.14)$ & $0.83(0.59-1.17)$ & $1.13(0.89-1.44)$ \\
\hline \multicolumn{5}{|l|}{ Wine consumption (residuals) } \\
\hline $\mathrm{N}$ & 1265 & 1264 & 1264 & 3793 \\
\hline Cases / Person Years & $78 / 6291$ & $87 / 6172$ & $54 / 6040$ & $219 / 18503$ \\
\hline HR (95\% CI): Model 1 & 1.00 (ref) & $1.20(0.88-1.64)$ & $0.87(0.61-1.24)$ & $0.90(0.79-1.03)$ \\
\hline HR (95\% CI): Model 2 & 1.00 (ref) & $1.16(0.84-1.59)$ & $0.85(0.59-1.22)$ & $0.88(0.76-1.01)$ \\
\hline HR (95\% CI): Model 3 & 1.00 (ref) & $1.03(0.66-1.37)$ & $0.95(0.66-1.37)$ & $0.90(0.78-1.04)$ \\
\hline \multicolumn{5}{|l|}{ Spirit consumption (residuals) } \\
\hline $\mathrm{N}$ & 1265 & 1266 & 1262 & 3793 \\
\hline Cases / Person Years & $54 / 6068$ & $87 / 6159$ & $78 / 6276$ & $219 / 18503$ \\
\hline HR (95\% CI): Model 1 & 1.00 (ref) & $1.43(1.01-2.02)$ & $1.18(0.83-1.69)$ & $1.09(0.95-1.26)$ \\
\hline HR (95\% CI): Model 2 & 1.00 (ref) & $1.41(0.99-2.00)$ & $1.19(0.83-1.70)$ & $1.12(0.97-1.29)$ \\
\hline HR (95\% CI): Model 3 & 1.00 (ref) & $1.14(0.79-1.63)$ & $1.04(0.72-1.49)$ & $1.08(0.93-1.26)$ \\
\hline
\end{tabular}


Supplemental Table 2 (continued). Hazard Ratios (HRs) and 95\% Confidence Intervals (CIs) of the associations between residuals of absolute consumption of beer, wine, and spirits and diabetes incidence in 10 European cohorts.

\begin{tabular}{|c|c|c|c|c|}
\hline EPIC-ELDERLY: Greece & Q1 & Q2 & Q3 & Per 6 g/d \\
\hline \multicolumn{5}{|l|}{ Beer consumption (residuals) } \\
\hline $\mathrm{N}$ & 1784 & 1775 & 1757 & 5316 \\
\hline Cases / Person Years & $251 / 19614$ & $296 / 19127$ & $268 / 19109$ & $815 / 57849$ \\
\hline HR (95\% CI): Model 1 & 1.00 (ref) & $1.48(1.24-1.76)$ & $1.29(1.09-1.54)$ & $1.04(0.96-1.12)$ \\
\hline HR (95\% CI): Model 2 & 1.00 (ref) & $1.46(1.23-1.74)$ & $1.26(1.06-1.50)$ & $1.02(0.94-1.10)$ \\
\hline HR (95\% CI): Model 3 & 1.00 (ref) & $1.39(1.17-1.66)$ & $1.20(1.00-1.43)$ & $1.03(0.95-1.12)$ \\
\hline \multicolumn{5}{|c|}{ Wine consumption (residuals) } \\
\hline $\mathrm{N}$ & 1769 & 1765 & 1782 & 5316 \\
\hline Cases / Person Years & $273 / 18828$ & $280 / 19263$ & $262 / 19759$ & $815 / 57849$ \\
\hline HR (95\% CI): Model 1 & 1.00 (ref) & $0.84(0.71-1.00)$ & $0.66(0.55-0.78)$ & $0.93(0.88-0.98)$ \\
\hline HR (95\% CI): Model 2 & 1.00 (ref) & $0.88(0.73-1.04)$ & $0.69(0.58-0.82)$ & $0.94(0.90-0.99)$ \\
\hline HR (95\% CI): Model 3 & 1.00 (ref) & $0.89(0.63-0.89)$ & $0.75(0.63-0.89)$ & $0.95(0.90-1.01)$ \\
\hline \multicolumn{5}{|c|}{ Spirit consumption (residuals) } \\
\hline $\mathrm{N}$ & 1770 & 1820 & 1726 & 5316 \\
\hline Cases / Person Years & $260 / 19497$ & $284 / 20037$ & $271 / 18315$ & $815 / 57849$ \\
\hline HR (95\% CI): Model 1 & 1.00 (ref) & $1.23(1.03-.46)$ & $1.49(1.26-1.78)$ & $1.08(1.02-1.14)$ \\
\hline HR (95\% CI): Model 2 & 1.00 (ref) & $1.21(1.02-1.45)$ & $1.45(1.22-1.72)$ & $1.06(1.01-1.12)$ \\
\hline HR (95\% CI): Model 3 & 1.00 (ref) & $1.12(0.94-1.34)$ & $1.35(1.13-1.61)$ & $1.05(0.99-1.11)$ \\
\hline
\end{tabular}


Supplemental Table 2 (continued). Hazard Ratios (HRs) and 95\% Confidence Intervals (CIs) of the associations between residuals of absolute consumption of beer, wine, and spirits and diabetes incidence in 10 European cohorts.

\begin{tabular}{|lllll|}
\hline EPIC-ELDERLY: Sweden & Q1 & Q2 & Q3 & Per 6 g/d \\
\hline Beer consumption (residuals) & & & & \\
\hline $\mathrm{N}$ & 932 & 949 & 936 & 2819 \\
\hline Cases / Person Years & $27 / 12276$ & $48 / 12507$ & $34 / 12400$ & $109 / 37183$ \\
\hline HR $(95 \%$ CI): Model 1 & $1.00(\mathrm{ref})$ & $1.99(1.22-3.25)$ & $1.14(0.68-1.91)$ & $0.99(0.48-2.03)$ \\
\hline HR $(95 \%$ CI): Model 2 & $1.00(\mathrm{ref})$ & $2.02(1.24-3.31)$ & $1.16(0.69-1.95)$ & $1.00(0.48-2.06)$ \\
\hline HR $(95 \%$ CI): Model 3 & $1.00(\mathrm{ref})$ & $1.99(1.22-3.77)$ & $1.31(0.78-2.22)$ & $1.20(0.56-2.56)$ \\
\hline Wine consumption (residuals) & & & & \\
\hline $\mathrm{N}$ & 941 & 921 & 957 & 2819 \\
\hline Cases / Person Years & $39 / 12435$ & $43 / 12173$ & $27 / 12576$ & $109 / 37183$ \\
\hline HR $(95 \%$ CI): Model 1 & $1.00(\mathrm{ref})$ & $1.31(0.83-2.08)$ & $0.85(0.50-1.45)$ & $0.54(0.23-1.29)$ \\
\hline HR $(95 \%$ CI): Model 2 & $1.00(\mathrm{ref})$ & $1.32(0.83-2.10)$ & $0.85(0.50-1.45)$ & $0.54(0.23-1.29)$ \\
\hline HR $(95 \%$ CI): Model 3 & $1.00(\mathrm{ref})$ & $1.21(0.46-1.35)$ & $0.79(0.46-1.35)$ & $0.44(0.17-1.10)$ \\
\hline Spirit consumption (residuals) & & & & \\
\hline $\mathrm{N}$ & 939 & 956 & 924 & 2819 \\
\hline Cases / Person Years & $21 / 12366$ & $43 / 12604$ & $45 / 12213$ & $109 / 37183$ \\
\hline HR (95\% CI): Model 1 & $1.00(\mathrm{ref})$ & $2.14(1.26-3.62)$ & $2.04(1.21-3.44)$ & $1.76(0.86-3.61)$ \\
\hline HR (95\% CI): Model 2 & $1.00(\mathrm{ref})$ & $2.13(1.26-3.63)$ & $2.02(1.19-3.43)$ & $1.76(0.85-3.64)$ \\
\hline HR (95\% CI): Model 3 & $1.00(\mathrm{ref})$ & $2.05(1.20-3.49)$ & $1.86(1.10-3.15)$ & $1.65(0.74-3.68)$ \\
\hline
\end{tabular}


Supplemental Table 2 (continued). Hazard Ratios (HRs) and 95\% Confidence Intervals (CIs) of the associations between residuals of absolute consumption of beer, wine, and spirits and diabetes incidence in 10 European cohorts.

\begin{tabular}{|lllll|}
\hline Tromsø & Q1 & Q2 & Q3 & Per 6 g/d \\
\hline Beer consumption (residuals) & & & & \\
\hline $\mathrm{N}$ & 1562 & 1752 & 1644 & 4958 \\
\hline Cases / Person Years & $79 / 20158$ & $97 / 22559$ & $102 / 21103$ & $278 / 63819$ \\
\hline HR $(95 \%$ CI): Model 1 & $1.00(\mathrm{ref})$ & $1.11(0.82-1.50)$ & $1.07(0.79-1.45)$ & $1.11(0.91-1.36)$ \\
\hline HR $(95 \%$ CI): Model 2 & $1.00(\mathrm{ref})$ & $1.11(0.82-1.50)$ & $1.07(0.79-1.45)$ & $1.11(0.91-1.36)$ \\
\hline HR $(95 \%$ CI): Model 3 & $1.00(\mathrm{ref})$ & $1.03(0.76-1.39)$ & $1.16(0.85-1.57)$ & $1.16(0.95-1.41)$ \\
\hline Wine consumption (residuals) & & & & \\
\hline $\mathrm{N}$ & 1662 & 1733 & 1563 & 4958 \\
\hline Cases / Person Years & $114 / 20596$ & $100 / 22534$ & $64 / 20689$ & $278 / 63819$ \\
\hline HR $(95 \%$ CI): Model 1 & $1.00(\mathrm{ref})$ & $0.92(0.70-1.21)$ & $0.70(0.50-0.97)$ & $0.88(0.71-1.09)$ \\
\hline HR $(95 \%$ CI): Model 2 & $1.00(\mathrm{ref})$ & $0.92(0.70-1.22)$ & $0.70(0.50-0.98)$ & $0.88(0.71-1.09)$ \\
\hline HR $(95 \%$ CI): Model 3 & $1.00(\mathrm{ref})$ & $0.95(0.56-1.10)$ & $0.79(0.56-1.10)$ & $0.91(0.73-1.15)$ \\
\hline Spirit consumption (residuals) & & & & \\
\hline $\mathrm{N}$ & 1708 & 1617 & 1633 & 4958 \\
\hline Cases / Person Years & $80 / 22496$ & $80 / 21103$ & $118 / 20220$ & $278 / 63819$ \\
\hline HR (95\% CI): Model 1 & $1.00(\mathrm{ref})$ & $1.02(0.75-1.40)$ & $1.41(1.05-1.91)$ & $1.07(0.74-1.54)$ \\
\hline HR (95\% CI): Model 2 & $1.00(\mathrm{ref})$ & $1.02(0.75-1.40)$ & $1.41(1.04-1.92)$ & $1.06(0.73-1.53)$ \\
\hline HR (95\% CI): Model 3 & $1.00(\mathrm{ref})$ & $0.85(0.62-1.16)$ & $1.08(0.79-1.46)$ & $0.84(0.57-1.25)$ \\
\hline
\end{tabular}


Supplemental Table 2 (continued). Hazard Ratios (HRs) and 95\% Confidence Intervals (CIs) of the associations between residuals of absolute consumption of beer, wine, and spirits and diabetes incidence in 10 European cohorts.

\begin{tabular}{|lllll|}
\hline ESTHER & Q1 & Q2 & Q3 & Per 6 g/d \\
\hline Beer consumption (residuals) & & & & \\
\hline $\mathrm{N}$ & 1589 & 1932 & 1765 & 5286 \\
\hline Cases / Person Years & $143 / 11176$ & $186 / 13686$ & $197 / 11731$ & $526 / 36593$ \\
\hline HR $(95 \%$ CI): Model 1 & $1.00(\mathrm{ref})$ & $1.08(0.86-1.34)$ & $1.12(0.89-1.40)$ & $1.06(0.95-1.18)$ \\
\hline HR $(95 \%$ CI): Model 2 & $1.00(\mathrm{ref})$ & $1.10(0.88-1.37)$ & $1.11(0.89-1.39)$ & $1.05(0.95-1.17)$ \\
\hline HR $(95 \%$ CI): Model 3 & $1.00(\mathrm{ref})$ & $1.07(0.86-1.34)$ & $1.05(0.84-1.32)$ & $1.05(0.94-1.16)$ \\
\hline Wine consumption (residuals) & & & & \\
\hline $\mathrm{N}$ & 1667 & 1792 & 1827 & 5286 \\
\hline Cases / Person Years & $191 / 11018$ & $175 / 12681$ & $160 / 12894$ & $526 / 36593$ \\
\hline HR $(95 \%$ CI): Model 1 & $1.00(\mathrm{ref})$ & $0.88(0.71-1.10)$ & $0.83(0.67-1.04)$ & $0.94(0.85-1.05)$ \\
\hline HR $(95 \%$ CI): Model 2 & $1.00(\mathrm{ref})$ & $0.90(0.72-1.13)$ & $0.84(0.67-1.06)$ & $0.95(0.85-1.05)$ \\
\hline HR $(95 \%$ CI): Model 3 & $1.00(\mathrm{ref})$ & $0.92(0.72-1.13)$ & $0.90(0.72-1.13)$ & $0.96(0.87-1.07)$ \\
\hline Spirit consumption (residuals) & & & & \\
\hline $\mathrm{N}$ & 1865 & 1834 & 1687 & 5286 \\
\hline Cases / Person Years & $166 / 12075$ & $184 / 12834$ & $176 / 11683$ & $526 / 36593$ \\
\hline HR (95\% CI): Model 1 & $1.00(\mathrm{ref})$ & $1.18(0.94-1.47)$ & $1.11(0.89-1.37)$ & $1.06(0.74-1.53)$ \\
\hline HR (95\% CI): Model 2 & $1.00(\mathrm{ref})$ & $1.20(0.96-1.49)$ & $1.12(0.91-1.39)$ & $1.05(0.73-1.51)$ \\
\hline HR (95\% CI): Model 3 & $1.00(\mathrm{ref})$ & $1.12(0.90-1.39)$ & $1.03(0.83-1.27)$ & $0.93(0.64-1.35)$ \\
\hline
\end{tabular}


Supplemental Table 2 (continued). Hazard Ratios (HRs) and 95\% Confidence Intervals (CIs) of the associations between residuals of absolute consumption of beer, wine, and spirits and diabetes incidence in 10 European cohorts.

\begin{tabular}{|lllll|}
\hline MORGAM: FINRISK & Q1 & Q2 & Q3 & Per 6 g/d \\
\hline Beer consumption (residuals) & & & & \\
\hline $\mathrm{N}$ & 6455 & 6069 & 7235 & 19759 \\
\hline Cases / Person Years & $645 / 103702$ & $493 / 99754$ & $572 / 114169$ & $1710 / 317624$ \\
\hline HR $(95 \%$ CI): Model 1 & $1.00(\mathrm{ref})$ & $0.82(0.73-0.92)$ & $0.96(0.86-1.08)$ & $0.97(0.93-1.02)$ \\
\hline HR $(95 \%$ CI): Model 2 & $1.00(\mathrm{ref})$ & $0.85(0.75-0.96)$ & $0.96(0.86-1.07)$ & $0.97(0.93-1.02)$ \\
\hline HR $(95 \%$ CI): Model 3 & $1.00(\mathrm{ref})$ & $0.95(0.84-1.07)$ & $1.09(0.97-1.22)$ & $1.02(0.98-1.07)$ \\
\hline Wine consumption (residuals) & & & & \\
\hline $\mathrm{N}$ & 6643 & 6477 & 6639 & 19759 \\
\hline Cases / Person Years & $705 / 108162$ & $548 / 108167$ & $457 / 101296$ & $1710 / 317624$ \\
\hline HR $(95 \%$ CI): Model 1 & $1.00(\mathrm{ref})$ & $0.81(0.72-0.91)$ & $0.79(0.69-0.89)$ & $0.95(0.88-1.02)$ \\
\hline HR $(95 \%$ CI): Model 2 & $1.00(\mathrm{ref})$ & $0.84(0.75-0.95)$ & $0.82(0.72-0.93)$ & $0.96(0.89-1.02)$ \\
\hline HR $(95 \%$ CI): Model 3 & $1.00(\mathrm{ref})$ & $0.95(0.78-1.01)$ & $0.89(0.78-1.01)$ & $0.98(0.92-1.04)$ \\
\hline Spirit consumption (residuals) & & & & \\
\hline $\mathrm{N}$ & 7069 & 6188 & 6502 & 19759 \\
\hline Cases / Person Years & $511 / 105964$ & $445 / 1005545$ & $754 / 111116$ & $1710 / 317624$ \\
\hline HR (95\% CI): Model 1 & $1.00(\mathrm{ref})$ & $0.81(0.71-0.92)$ & $1.03(0.92-1.16)$ & $1.06(1.01-1.11)$ \\
\hline HR (95\% CI): Model 2 & $1.00(\mathrm{ref})$ & $0.85(0.75-0.97)$ & $1.05(0.94-1.18)$ & $1.05(1.01-1.10)$ \\
\hline HR (95\% CI): Model 3 & $1.00(\mathrm{ref})$ & $0.83(0.73-0.95)$ & $0.92(0.82-1.03)$ & $0.99(0.94-1.03)$ \\
\hline
\end{tabular}


Supplemental Table 2 (continued). Hazard Ratios (HRs) and 95\% Confidence Intervals (CIs) of the associations between residuals of absolute consumption of beer, wine, and spirits and diabetes incidence in 10 European cohorts.

\begin{tabular}{|lllll|}
\hline MORGAM: MOLI-SANI & Q1 & Q2 & Q3 & Per 6 g/d \\
\hline Beer consumption (residuals) & & & & \\
\hline $\mathrm{N}$ & 4811 & 5065 & 4634 & 14510 \\
\hline Cases / Person Years & $110 / 20994$ & $117 / 22226$ & $68 / 20533$ & $295 / 63753$ \\
\hline HR $(95 \%$ CI): Model 1 & $1.00(\mathrm{ref})$ & $1.32(1.00-1.74)$ & $1.04(0.76-1.42)$ & $1.04(0.92-1.18)$ \\
\hline HR $(95 \%$ CI): Model 2 & $1.00(\mathrm{ref})$ & $1.33(1.00-1.75)$ & $1.04(0.76-1.42)$ & $1.04(0.92-1.17)$ \\
\hline HR $(95 \%$ CI): Model 3 & $1.00(\mathrm{ref})$ & $1.26(0.95-1.66)$ & $1.03(0.75-1.41)$ & $1.01(0.90-1.14)$ \\
\hline Wine consumption (residuals) & & & & \\
\hline $\mathrm{N}$ & 4797 & 5271 & 4442 & 14510 \\
\hline Cases / Person Years & $75 / 21702$ & $115 / 23140$ & $105 / 18911$ & $295 / 63753$ \\
\hline HR $(95 \%$ CI): Model 1 & $1.00(\mathrm{ref})$ & $1.15(0.85-1.56)$ & $0.97(0.71-1.33)$ & $0.98(0.87-1.10)$ \\
\hline HR $(95 \%$ CI): Model 2 & $1.00(\mathrm{ref})$ & $1.16(0.85-1.57)$ & $0.97(0.71-1.33)$ & $0.98(0.87-1.10)$ \\
\hline HR $(95 \%$ CI): Model 3 & $1.00(\mathrm{ref})$ & $1.14(0.73-1.36)$ & $1.00(0.73-1.36)$ & $1.00(0.89-1.12)$ \\
\hline Spirit consumption (residuals) & & & & \\
\hline N & 4750 & 5075 & 4685 & 14510 \\
\hline Cases / Person Years & $104 / 19857$ & $106 / 22123$ & $85 / 21772$ & $295 / 63753$ \\
\hline HR (95\% CI): Model 1 & $1.00(\mathrm{ref})$ & $1.23(0.92-1.64)$ & $1.08(0.80-1.45)$ & $0.93(0.68-1.27)$ \\
\hline HR (95\% CI): Model 2 & $1.00(\mathrm{ref})$ & $1.23(0.92-1.65)$ & $1.09(0.81-1.46)$ & $0.93(0.68-1.27)$ \\
\hline HR (95\% CI): Model 3 & $1.00(\mathrm{ref})$ & $1.21(0.91-1.62)$ & $1.02(0.76-1.37)$ & $0.93(0.69-1.26)$ \\
\hline
\end{tabular}


Supplemental Table 2 (continued). Hazard Ratios (HRs) and 95\% Confidence Intervals (CIs) of the associations between residuals of absolute consumption of beer, wine, and spirits and diabetes incidence in 10 European cohorts.

\begin{tabular}{|c|c|c|c|c|}
\hline MORGAM: North-Sweden & Q1 & $\mathbf{Q 2}$ & Q3 & Per 6 g/d \\
\hline \multicolumn{5}{|l|}{ Beer consumption (residuals) } \\
\hline $\mathrm{N}$ & 1101 & 911 & 1020 & 3032 \\
\hline Cases / Person Years & $55 / 21790$ & 44 / 18329 & $50 / 19628$ & 149 / 59748 \\
\hline HR (95\% CI): Model 1 & 1.00 (ref) & $1.11(0.74-1.65)$ & $1.04(0.70-1.55)$ & $1.44(0.84-2.46)$ \\
\hline HR (95\% CI): Model 2 & 1.00 (ref) & $1.15(0.77-1.73)$ & $1.11(0.74-1.65)$ & $1.46(0.87-2.47)$ \\
\hline HR (95\% CI): Model 3 & 1.00 (ref) & $1.15(0.77-1.72)$ & $1.11(0.75-1.66)$ & $1.49(0.86-2.60)$ \\
\hline \multicolumn{5}{|l|}{ Wine consumption (residuals) } \\
\hline $\mathrm{N}$ & 784 & 1224 & 1024 & 3032 \\
\hline Cases / Person Years & $40 / 14853$ & $63 / 24261$ & $46 / 20633$ & $149 / 59748$ \\
\hline HR (95\% CI): Model 1 & 1.00 (ref) & $0.96(0.64-1.44)$ & $0.93(0.58-1.48)$ & $0.87(0.44-1.69)$ \\
\hline HR (95\% CI): Model 2 & 1.00 (ref) & $0.98(0.65-1.48)$ & $0.92(0.57-1.48)$ & $0.87(0.45-1.67)$ \\
\hline HR (95\% CI): Model 3 & 1.00 (ref) & $0.99(0.66-1.68)$ & $1.05(0.66-1.68)$ & $0.98(0.49-1.96)$ \\
\hline \multicolumn{5}{|l|}{ Spirit consumption (residuals) } \\
\hline $\mathrm{N}$ & 1042 & 1012 & 978 & 3032 \\
\hline Cases / Person Years & $46 / 20310$ & $47 / 20377$ & $56 / 19060$ & $149 / 59748$ \\
\hline HR (95\% CI): Model 1 & 1.00 (ref) & $0.98(0.65-1.48)$ & $1.09(0.72-1.65)$ & $0.93(0.68-1.27)$ \\
\hline HR (95\% CI): Model 2 & 1.00 (ref) & $0.99(0.66-1.50)$ & $1.05(0.70-1.60)$ & $0.67(0.29-1.54)$ \\
\hline HR (95\% CI): Model 3 & 1.00 (ref) & $0.89(0.59-1.34)$ & $0.88(0.58-1.33)$ & $0.51(0.21-1.26)$ \\
\hline
\end{tabular}

Model 1: Adjusted for age, sex, education, employment, and prevalent coronary heart disease or cancer;

Model 2: Model 1 additionally adjusted for smoking status, sports activity (if available), and Healthy Diet Indicator score (if available).

Model 3: Model 2 additionally adjusted for BMI. 
Table 1. Cohort characteristics of the ten included European cohorts from the Consortium on Health and Ageing: Network of Cohorts in Europe and the United States (CHANCES) project and number of included persons who reported to consume alcohol.

\begin{tabular}{|c|c|c|c|c|c|c|c|c|}
\hline Cohort & $\begin{array}{l}\text { Sub-cohort or } \\
\text { country }\end{array}$ & $\begin{array}{l}\text { Baseline } \\
\text { period }\end{array}$ & $\begin{array}{l}\text { Follow- } \\
\text { up } \\
\text { period }\end{array}$ & $\begin{array}{l}\text { Follow-up } \\
\text { length, } \\
\text { median [P25- } \\
\text { P75] }\end{array}$ & Ascertainment of incident diabetes type 2 & $\mathbf{N}$ & $\begin{array}{l}\text { Age } \\
\text { category }\end{array}$ & $\begin{array}{l}\text { Males, } \\
\%\end{array}$ \\
\hline $\begin{array}{l}\text { Zutphen } \\
\text { Elderly Study }\end{array}$ & $\begin{array}{l}\text { The } \\
\text { Netherlands }\end{array}$ & 1985 & $\begin{array}{l}1985- \\
2010\end{array}$ & $9.7[5.0-15.0]$ & $\begin{array}{l}\text { Self-report and current treatment and non- } \\
\text { fasting glucose measures using the WHO } \\
\text { definition }^{46} \text {. }\end{array}$ & 557 & $\geq 60 y$ & 100 \\
\hline $\begin{array}{l}\text { Rotterdam } \\
\text { Study }\end{array}$ & $\begin{array}{l}\text { The } \\
\text { Netherlands }\end{array}$ & 1990 & $\begin{array}{l}1997- \\
2013\end{array}$ & $\begin{array}{l}12.2[7.0- \\
13.1]\end{array}$ & $\begin{array}{l}\text { Followed-up using information from general } \\
\text { practitioners, pharmacies' databases, and } \\
\text { follow-up examinations. Defined as being } \\
\text { registered by a general practitioner as having } \\
\text { type } 2 \text { diabetes and meeting at least one of } \\
\text { the following four criteria: fasting plasma } \\
\text { glucose concentration } \geq 7.0 \mathrm{mmol} / \mathrm{L}, \text { random } \\
\text { plasma glucose concentration } \geq 11.1 \mathrm{mmol} / \mathrm{L} \text {, } \\
\text { use of anti-diabetic mediation, and/or } \\
\text { following dietary guidelines for type } 2 \\
\text { diabetes. }\end{array}$ & 2428 & $\geq 55 \mathrm{y}$ & 44 \\
\hline EPIC-EIderly & $\begin{array}{l}\text { The } \\
\text { Netherlands }\end{array}$ & $\begin{array}{l}1993- \\
1997\end{array}$ & $\begin{array}{l}1993- \\
2005\end{array}$ & $4.9[4.1-5.0]$ & $\begin{array}{l}\text { Self-reported diagnosis in the follow-up } \\
\text { questionnaires and/or a urinary glucose strip } \\
\text { test for detection of glucosuria, and/or } \\
\text { linkage with the Dutch register of hospital } \\
\text { discharge diagnoses }{ }^{47} \text {. }\end{array}$ & 3793 & $\geq 60 y$ & 6 \\
\hline
\end{tabular}


Table 1 (continued). Cohort characteristics of the ten included European cohorts from the Consortium on Health and Ageing: Network of

Cohorts in Europe and the United States (CHANCES) project and number of included persons who reported to consume alcohol.

\begin{tabular}{|c|c|c|c|c|c|c|c|c|}
\hline Cohort & $\begin{array}{l}\text { Sub-cohort or } \\
\text { country }\end{array}$ & $\begin{array}{l}\text { Baseline } \\
\text { period }\end{array}$ & $\begin{array}{l}\text { Follow- } \\
\text { up } \\
\text { period }\end{array}$ & $\begin{array}{l}\text { Follow-up } \\
\text { length, } \\
\text { median [P25- } \\
\text { P75] }\end{array}$ & Ascertainment of incident diabetes type 2 & $\mathbf{N}$ & $\begin{array}{l}\text { Age } \\
\text { category }\end{array}$ & $\begin{array}{l}\text { Males, } \\
\%\end{array}$ \\
\hline & Greece & $\begin{array}{l}1994- \\
1999\end{array}$ & $\begin{array}{l}1994- \\
2011\end{array}$ & $\begin{array}{l}11.4 \text { [9.9- } \\
12.5]\end{array}$ & $\begin{array}{l}\text { Collected during follow-up through self- } \\
\text { report and current treatment; cases were not } \\
\text { validated. }\end{array}$ & 5316 & $\geq 60 y$ & 50 \\
\hline & Sweden & $\begin{array}{l}1992- \\
1996\end{array}$ & $\begin{array}{l}1992- \\
2011\end{array}$ & $\begin{array}{l}13.2[12.1- \\
14.2]\end{array}$ & $\begin{array}{l}\text { Followed up through linkage with the } \\
\text { Swedish diabetes register and verified by } \\
\text { biomarker measurements of impaired } \\
\text { glucose tolerance and impaired fasting } \\
\text { glucose in a few cases. }\end{array}$ & 2819 & $\geq 60 \mathrm{y}$ & 51 \\
\hline $\begin{array}{l}\text { The Tromsø } \\
\text { Study }\end{array}$ & Norway & $\begin{array}{l}1994- \\
1995\end{array}$ & $\begin{array}{l}1994- \\
2010\end{array}$ & $\begin{array}{l}15.6[10.0- \\
16.0]\end{array}$ & 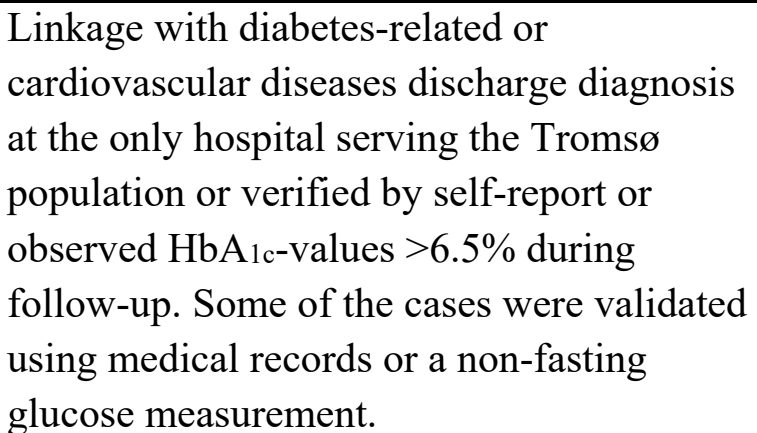 & 4958 & $\geq 45 \mathrm{y}$ & 59 \\
\hline
\end{tabular}


Table 1 (continued). Cohort characteristics of the ten included European cohorts from the Consortium on Health and Ageing: Network of

Cohorts in Europe and the United States (CHANCES) project and number of included persons who reported to consume alcohol.

\begin{tabular}{|c|c|c|c|c|c|c|c|c|}
\hline Cohort & $\begin{array}{l}\text { Sub-cohort or } \\
\text { country }\end{array}$ & $\begin{array}{l}\text { Baseline } \\
\text { period }\end{array}$ & $\begin{array}{l}\text { Follow- } \\
\text { up } \\
\text { period }\end{array}$ & $\begin{array}{l}\text { Follow-up } \\
\text { length, } \\
\text { median [P25- } \\
\text { P75] }\end{array}$ & Ascertainment of incident diabetes type 2 & $\mathbf{N}$ & $\begin{array}{l}\text { Age } \\
\text { category }\end{array}$ & $\begin{array}{l}\text { Males, } \\
\%\end{array}$ \\
\hline ESTHER & Germany & $\begin{array}{l}2000- \\
2003\end{array}$ & $\begin{array}{l}2000- \\
2007\end{array}$ & $7.9[5.3-8.1]$ & $\begin{array}{l}\text { The cohort was systematically searched for } \\
\text { diabetes events and incident cases were } \\
\text { validated with medical records during } \\
\text { follow-up. In addition, subjects with } \mathrm{HbA}_{1 \mathrm{c}} \\
\geq 6.5 \% \text { at } 8 \text {-year follow-up were classified } \\
\text { as subjects with incident type } 2 \text { diabetes in } \\
\text { order to identify undiagnosed cases. }\end{array}$ & 5286 & $48-75 y$ & 53 \\
\hline \multirow[t]{3}{*}{ MORGAM } & $\begin{array}{l}\text { FINRISK } \\
\text { (Finland) }\end{array}$ & $\begin{array}{l}1982- \\
2002\end{array}$ & $\begin{array}{l}1982- \\
2010\end{array}$ & $\begin{array}{l}14.0[8.9- \\
23.8]\end{array}$ & $\begin{array}{l}\text { Through linkage to the national Hospital } \\
\text { Discharge Register, Causes of Death } \\
\text { Register, and drug reimbursement } \\
\text { registers }{ }^{48} \text {. }\end{array}$ & 19759 & $24-74$ y & 57 \\
\hline & $\begin{array}{l}\text { MOLI-SANI } \\
\text { (Italy) }\end{array}$ & $\begin{array}{l}2005- \\
2010\end{array}$ & $\begin{array}{l}2005- \\
2011\end{array}$ & $4.3[3.3-5.4]$ & $\begin{array}{l}\text { Cases were identified and validated through } \\
\text { linkage to the National Medication Register } \\
\text { and to the Local Diagnosis Registers }{ }^{48} \text {. }\end{array}$ & 14510 & $35-99$ y & 60 \\
\hline & $\begin{array}{l}\text { Northern- } \\
\text { Sweden } \\
\text { (Sweden) }\end{array}$ & $\begin{array}{l}1986- \\
1994\end{array}$ & $\begin{array}{l}1986- \\
2011\end{array}$ & $\begin{array}{l}20.8[17.8- \\
24.5]\end{array}$ & $\begin{array}{l}\text { Based on self-reported diagnosis in a phone } \\
\text { interview and/or linkage with Hospital } \\
\text { Discharge Records }{ }^{48} \text {. }\end{array}$ & 3032 & $24-74 \mathrm{y}$ & 58 \\
\hline
\end{tabular}


Table 2. Pooled Hazard Ratios (95\% CI) from random-effects meta-analyses for the association between having a beer, wine, or spirit preference compared to having no preference according to sub-groups and additional analyses.

\begin{tabular}{|c|c|c|c|c|}
\hline & Beer preference & Wine preference & Spirit preference & No preference \\
\hline \multicolumn{5}{|l|}{ BMI } \\
\hline$-\quad<25 \mathrm{~kg} / \mathrm{m}^{2}$ & $1.24(0.95-1.61)$ & $1.07(0.85-1.36)$ & $0.89(0.44-1.82)$ & 1.00 (ref) \\
\hline$-\quad \geq 25 \mathrm{~kg} / \mathrm{m}^{2}$ & $1.05(0.95-1.15)$ & $0.95(0.85-1.06)$ & $1.26(1.06-1.51)$ & 1.00 (ref) \\
\hline \multicolumn{5}{|l|}{ Sex } \\
\hline - Men & $1.26(0.93-1.71)$ & $1.17(0.92-1.50)$ & $1.27(1.01-1.59)$ & 1.00 (ref) \\
\hline - Women & $1.23(0.89-1.70)$ & $1.08(0.85-1.37)$ & $1.33(1.11-1.60)$ & 1.00 (ref) \\
\hline Excluding persons with prevalent diseases* & $1.04(0.95-1.15)$ & $0.99(0.87-1.13)$ & $1.16(0.95-1.42)$ & 1.00 (ref) \\
\hline Additional adjustment for frequency pattern & $1.05(0.95-1.16)$ & $0.98(0.87-1.10)$ & $1.01(0.90-1.14)$ & 1.00 (ref) \\
\hline Definition alcoholic beverage preference with cut-off $50 \%$ & $1.06(0.93-1.21)$ & $0.93(0.77-1.12)$ & $1.10(0.93-1.31)$ & 1.00 (ref) \\
\hline
\end{tabular}

* Defined as persons with prevalent heart disease or cancer or a follow-up $\leq 2$ years.

Models adjusted for age, sex, education, employment, prevalent coronary heart disease or cancer, smoking status, sports activity (if available), Healthy Diet Indicator score (if available), and BMI. 